\title{
SOBRE EL CAMPO SEMÁNTICO DE LA POLÍTICA EN EURÍPIDES
}

This paper analyses the lexical items which have a political function in Euripides' plays. The method employed is perhaps valid for other studies in Semantics. The study has been based on the following main concepts: 1. Tipology of context. 2. Semantic nuclei and their typology. A semantic nucleus consists of "key-words" or «key-phrases» around which the lexical items semantically cohere and oppositions are systematically established. 3. The distribution of the lexical items, polarized and re-categorized around the terms which form the semantic nucleus, by means of mechanisms similar to those which operate on grammatical categories.

\section{Generalidades}

En el VII Congreso español de Estudios Clásicos presenté una Comunicación, que era adelanto de este otro trabajo, más completo. Su título era "Anticipo sobre el léxico politico de Eurípides»' '. Allí enfocaba mi exposición en dos aspectos: en un primer aspecto presentaba cuestiones de método y algunas conclusiones provisionales de carácter general; y, en un segundo aspecto, pasaba a ejemplificar la teoría general utilizando para ello Las Suplicantes.

En este trabajo amplío los puntos de vista generales, ya que un análisis más completo de los datos me ha llevado a nuevas conclusiones. En él realizo asimismo un estudio más completo del campo semántico de la política en Euripides ${ }^{2}$.

1 El título que daba a mi comunicación «Anticipo sobre el léxico político de Euripides" contenia una imprecisión en la terminologia. Yo considero que en Ifigenia en Áulide el procedimiento de oponer nociones no se realiza, como en el resto de las obras, a través de la semántica del léxico concreto, sino a través de unidades más amplias, o sea, a través de los sintagmas. En otras palabras, en el nivel de la relación entre las categorias léxicas y las gramaticales, en consecuencia, no sólo entra en juego en este trabajo el léxico, sino también el sintagma.

2 Desde el punto de vista teórico nuestro estudio se mueve dentro de la doctrina 
1.1. El material que he estudiado minuciosamente es el siguiente. Las obras Hécuba, Los Heraclidas, Andrómaca, Las Suplicantes, Las Fenicias e Ifigenia en Áulide.

En una segunda fase he estudiado, en las restantes tragedias, los términos que desempeñan funcionalidad política en las obras citadas arriba. He comprobado que en las demás obras de Eurípides sólo muy esporádicamente desempeñan esa funcionalidad. Por esa razón las he estimado no pertinentes a mi objetivo.

Del estudio de este material he extraído conclusiones que se pueden llamar de método, que conciernen a los siguientes aspectos: 1. Delimitación del léxico político. 2. Delimitación del contexto y sus tipologias. 3 . Concepto de núcleo y sus tipologías.

Me voy a referir a continuación a estos tres aspectos de tipo metodológico.

1.2. Están de una parte los términos que hacen referencia a Órganos políticos - Bulé, Asamblea, etc.-. Estos términos constituyen un léxico político per se y el rasgo que los caracteriza es que su referente es univoco. Este léxico no es el más numeroso, ni tampoco el más importante. Aparte de estos términos que hacen referencia a órganos politicos, o a formas de gobierno, no existe un léxico propiamente político

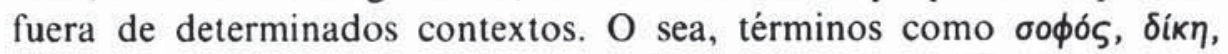
xápıs tienen dos rasgos que los caracterizan: no son políticos per se, ni tienen un referente univoco. Lo que se puede decir de ellos es que su función los define como políticos y que esa funcionalidad es de muy alta frecuencia ${ }^{3}$.

En este estudio me ocupo exclusivamente de este segundo tipo de términos. Los términos funcionalmente políticos proceden de diferentes

\footnotetext{
de "campo lingüistico" de J. Trier, Der deutsche Wortschatz im Sinnbezirk des Verstandes. Die Geschichte eines sprachlichen Feldes, Heidelberg 1931. Y dentro del estructuralismo funcional de E. Coseriu en Principios de semántica estructural, Madrid, Gredos, 1977, y Gramática, Semántica, Universales. Estudios de lingüistica funcional, Madrid, Gredos, 1978, y Geckeler, Semántica estructural y teoria del campo léxico. Madrid, Gredos, 1976; y del estructuralismo de F. R. Adrados, explicado desde un punto de vista teórico en su Lingüistica estructural, Madrid, Gredos, 1969, vol. I, cap. 8, pp. 490-544, y aplicado en algunos trabajos como «El campo semántico del amor en Safo», "El sistema de Heráclito: estudio a partir del léxico» y "Lengua, Ontología y Lógica en los Sofistas y Platón», todos compilados en Estudios de Semántica y Sintaxis, Barcelona 1975.

${ }_{3}$ Cf. sobre la extensión del léxico de propaganda política W. W. Donlan, «Social vocabulary and its relationship to political propaganda in fifth-century Athens", QUCC 27, 1978, pp. 95-111.
} 
campos semánticos: el del pensamiento, el de la acción, el de los sentimientos, el religioso, el ético ${ }^{4}$.

En las tragedias de Eurípides se encuentra uno con términos que

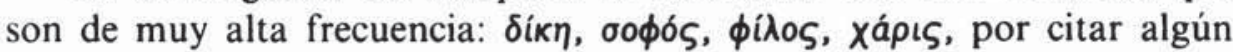
ejemplo. En cambio, palabras frecuentísimas en Tucidides y procedentes de la Sofística y el pensamiento jonio en general, como áváykn, son de poca frecuencia ${ }^{5}$. Este término se encuentra, usado con funcionalidad política, en una obra tardía como Ifigenia en Áulide.

1.3. Lo que define los términos como funcionalmente políticos es el contexto. Es preciso, por tanto, delimitar con mucha precisión qué se entiende por contexto. Se entiende por contexto el amplio de la obra en cuestión y el más reducido del pasaje. Pero se puede observar que en Eurípides el contexto de los pasajes donde los términos desempeñan funcionalidad política son sobre todo los estructurados en antilogías. Con antilogias hago referencia tanto a las resis, como a las composiciones dialógicas.

En las obras que he analizado se encuentran dos tipologías. En tres de ellas - Hécuba, Andrómaca y Las Suplicantes - el vocabulario que desempeña funcionalidad política está muy localizado sólo en las estructuras antilógicas. Las tres presentan la misma tipología. Éstos son los esquemas:

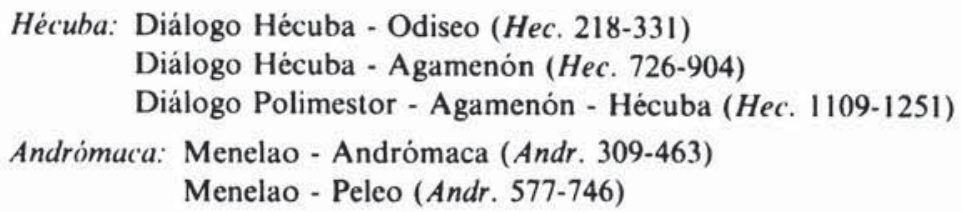

Las Suplicantes: Diálogo Teseo - embajador de Tebas (Supp. 399-597)

La otra tipologia tiene una estructura literaria y conceptual más compleja, consistente en: Unidades literarias que anticipan - NúcleoUnidades literarias que recurren sobre el núcleo cerrando.

Esta tipologia del contexto es la que se da en Los Heraclidas, Las Fenicias e Ifigenia en Áulide:

\footnotetext{
4 Coincido con muchos puntos de vista, estudiados desde otra perspectiva, que se encuentran en obras como las de A. W. H. Adkins, Merit and Responsibility, Oxford 1960, y en concreto en su artículo "Values in Euripides' Hecuba and Hercules Furens", $C Q 16,1966$, pp. 193-219. También con muchos puntos de vista sustentados por W. K. C. Guthrie en el vol. III de A History of Greek Philosophy, Cambridge 1969.

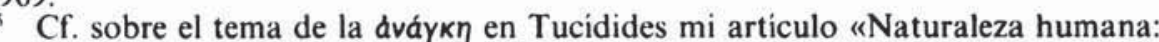
Teoria y Praxis en Tucidides", en Athlon... in honorem $F$. $R$. Adrados, vol. II, Madrid, Gredos, 1987, pp. 873-881. Alli se recoge además bibliografia sobre el tema.
} 


\section{Los Heraclidas:}

Anticipación: Prólogo de Yolao (Heracl. 1-54)

Diálogo Yolao - embajador de Argos (Heracl. 55-72)

Lirico coro - Yolao - embajador (Heracl. 73-119)

Núcleo: Resis del embajador - Resis de Yolao - Resis de Demofonte (Heracl. 134-252)

Estructura dialógica entre Demofonte y el embajador (Heracl. 253-287)

Cierre recurrente: Diálogo Yolao - Demofonte (Heracl. 297-352)

Cantos corales (Heracl. 353-380, 608-629, 748-783, 892-927)

\section{Las Fenicias:}

Anticipación: Diálogo Polinices - Yocasta (Ph. 357-442)

Diálogo Eteocles - Yocasta (Ph. 446-468)

Núcleo: Resis Polinices - Resis de Eteocles - Resis de Yocasta (Ph. 469-585)

Cierre recurrente: Diálogo Polinices - Eteocles ( $P h .588-637)$

Ifigenia en Áulide:

Anticipación: Diálogo lírico Agamenón - anciano (I.A. 16-27)

Núcleo: Esticomitia Agamenón-Menelao (I.A. 317-333)

Resis de Menelao - Resis de Agamenón (I.A. 334-401)

Esticomitia Agamenón - Menelao (I.A. 404-414)

Resis de Agamenón - Resis de Menelao (I.A. 440-503)

Diálogo Agamenón - Menelao (I.A. 506-542)

Cierre con nociones recurrentes: Resis de Aquiles (I.A. 919-974)

Resis de Ifigenia (I.A. 1368-1401)

1.4. Dentro del contexto surge otra interrogante más compleja: ¿En razón a qué noción o a qué nociones se realizan los distintos términos como funcionalmente políticos? Por ejemplo, qué determina que en un contexto concreto xpqorós signifique 'útil' y en otro 'moralmente honesto', o bien qué determina que ooфós en un lugar sea «aceptar las circunstancias tal como se presentan, adecuándose a ellas" y en otro "no mezclar a los hombres injustos con los justos».

Existe siempre en las obras de Eurípides que he estudiado un núcleo en torno al que se cohesiona semánticamente el resto del vocabulario.

Este núcleo, que constituye la noción central, es el encargado de desambiguar al léxico restante por procedimientos iguales a los que son operativos en las categorias gramaticales: distribuyéndolos, polarizándolos y recategorizándolos.

El núcleo lo constituye lo que se denominan "palabras clave». Su rasgo pertinente suele consistir en que son recurrentes. Pero no siempre 
es así. Puede tratarse de términos cuya repetición no es sistemática; su rasgo pertinente es otro en consecuencia ya que son igualmente «palabras clave». En Las Fenicias se trata de términos opuestos usados por un mismo hablante en texto contiguo, y trasvasados del nivel de la cosificación, aunque ella sea abstracta, al de la personificación. En esta obra éste es el rasgo pertinente, no la recurrencia.

Otras veces no se puede hablar de "palabras clave", sino de "sintagmas clave» que constituyen el núcleo semántico. Esto sucede en Ifigenia en Áulide, donde se da el sintagma recurrente a veces, pero otras veces sintagmas variables son portadores de nociones recurrentes. pides.

El núcleo semántico presenta tres tipos en las tragedias de Euri-

1.4.1. El núcleo está constituido por el mismo término jugando en dos parámetros distintos, haciendo referencia a nociones diferentes que entran en conflicto. El léxico restante se cohesiona semánticamente en torno a uno u otro término.

1.4.2. El núcleo está constituido por dos términos diferentes, que hacen referencia a nociones opuestas que entran en conflicto.

1.4.3. El tercer procedimiento consiste en oponer nociones que no se realizan en la semántica del léxico concreto, sino en la de los sintagmas, o sea, en el nivel de la relación entre las categorías léxicas y las gramaticales, mediante la semántica del texto.

Hay un problema importante en el que es preciso detenerse. El de la delimitación entre el lenguaje a nivel del personaje y el concepto de núcleo y cohesión semántica de términos o sintagmas con funcionalidad politica.

Las "palabras clave» o los "sintagmas clave» no siempre guardan relación directa con el lenguaje que caracteriza a uno $\mathrm{u}$ otro personaje, no siempre son patrimonio exclusivo de uno u otro. Lo mismo ocurre con el léxico que se cohesiona semánticamente con una otra noción nuclear. Puede estar en labios de personajes ideológicamente enfrentados. No es posible establecer cortes netos entre personajes si uno estudia el léxico funcionalmente político en la obra de Eurípides, porque en ella se dan argumentos enfrentados en cada personaje. Hay, pues, desdoblamientos aparentes de personalidad, y esto lo refleja la elección del léxico, su distribución y polarización.

Hay dos enfoques distintos: uno de ellos es de tipo sociolingüístico, 
que no hago aqui ${ }^{6}$. Este enfoque estudiaria el léxico al nivel del lenguaje del personaje - Hécuba, Odiseo, etc.- En este tipo de estudio se encuentra que un personaje como Hécuba siempre utilizará el término

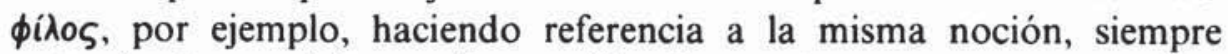
cada término tendrá un referente fijo. Esto es importante, porque sucede que el término en cuestión adquiere un significado concreto, o sea, tiene como referente una noción concreta y solamente ésa, al quedar ensamblado en el entramado semántico constituido por el código de ideas y vivencias del hablante que lo emplea. Así, pues, al hablar de contexto se hace referencia tanto al que está presente en el texto, como al que está ausente del texto, pero compone todo el campo referencial de cada hablante: el campo de su historia, sus vivencias, sus criterios, sus compromisos con la sociedad.

El otro enfoque, que es el que preside este estudio, es más complejo porque se mueve en una superestructura - el campo semántico de la política - integrada por múltiples infraestructuras - los niveles de lenguaje de personajes ideológica y vitalmente enfrentados-. Y éstos a su vez conducen los hilos de su discurso en diferentes parámetros. Por ejemplo, si tomamos Hécuba como punto de referencia, porque es una obra especialmente compleja, se observa lo siguiente: la superestructura la constituye la oposición entre dos nociones de xápıs. Las infraestructuras, los niveles de lenguaje de Hécuba, Odiseo, Agamenón y Polimestor.

Los diferentes parámetros se ven bien en el hecho de que Hécuba hable de una xápıs positiva en el nivel de las relaciones entre individuos, y de una xápıৎ negativa en el nivel de las relaciones entre el individuo y el estado.

\section{El MISMO TÉRMINO HACE REFERENCIA A DOS NOCIONES DISTINTAS}

2.1. En Hécuba el término recurrente es xápıs. Éste es el que constituye el núcleo semántico. Lo emplean los cuatro personajes a que hice referencia en la introducción: Hécuba, Odiseo, Agamenón y Polimestor.

El mismo término - xápıৎ - hace referencia a dos nociones diferentes. Hay una xápıs positiva, cuyo rasgo pertinente es su carácter absoluto, no coyuntural. Y una xápıৎ negativa, cuyo rasgo pertinente es su carácter coyuntural y mutable.

- Este tipo de estudio lo he ensayado en «La distribución y la polarización del léxico como rasgo relevante en sociolingüistica. Ejemplificación sobre la Antigona de Sófocles", RSEL 17, 1, 1987, pp. 85-94. 
Tanto una como otra se consideran en dos niveles: I) En el nivel de las relaciones entre individuos y 2) En el nivel de las relaciones entre el individuo y el estado.

La xápıs positiva consiste en "el agradecimiento por el favor recibido y en la manifestación de dicho agradecimiento mediante la devolución del favor, cuando la ocasión lo requiere así».

En el primer nivel, el de las relaciones entre individuos, ésta es la xápıs de que habla Hécuba a Odiseo primero y luego a Agamenón ${ }^{7}$. En el mismo nivel está la xápıs a la que estaba obligado Polimestor por el vínculo de $\zeta \varepsilon v i ́ a$ y que incumple ${ }^{8}$.

En el segundo nivel, el de las relaciones entre el individuo y el estado, es «el tributo de reconocimiento que el estado rinde al hombre que ha puesto la vida a su servicio». Esta es la xápıs que Odiseo dice que el pueblo griego debe a Aquiles ${ }^{9}$.

La xápıৎ negativa consiste: de una parte «en el favor que el pueblo otorga al hombre de estado» de que habla Hécuba, y de otra parte "en el favor que el hombre de estado busca del pueblo" de que habla Polimestor ${ }^{10}$.

El panorama es muy complejo porque las nociones de Xápıs en sus dos niveles están entrecruzadas con los conceptos en torno a dónde es-

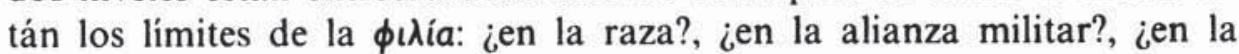
conducta, al margen de la raza y la alianza militar?

Así sucede que en torno a las distintas nociones de xápıৎ los términos se distribuyen todos. Un solo término es el que se polariza y éste justamente es $\phi i \lambda o \zeta$, lo que significa que los distintos interlocutores usan el mismo término con referentes distintos, o sea, lo manipulan.

En lo que concierne a la distribución del léxico, en el nivel de las relaciones entre los individuos, encontramos una xápıs positiva en un haz, en otro haz no hay una xápıs negativa, sino el no cumplimiento de la xápıs positiva, a lo que se suman otros varios rasgos pertinentes.

La xápıs positiva entre individuos consiste en el favor que Hécuba pide a Odiseo de que salve la vida de su hija Políxena en respuesta al favor que ella le hizo antaño. Consiste también en el favor que Hécuba pide a Agamenón de que le permita castigar a Polimestor a cambio del favor que él recibe de su amante Casandra.

No hay a su lado una xápıs negativa, como decía antes. Lo que en

7 Hec. 276 y 830.

* Hec. $736-863$ y $1187-1254$.

y Hec. 320.

10 Hec. 257 y 1175 ss. respectivamente. 
la obra se presenta como contrapartida es la conducta de Polimestor para con la familia de Príamo. O sea, una conducta que consiste en el no cumplimiento de la xápıৎ debida, pero cuyo rasgo pertinente no es ése, sino la violación del vínculo de そ̌vía por el asesinato del hijo de Hécuba.

Este panorama lo refleja muy bien la distribución del léxico. Éste es el esquema:

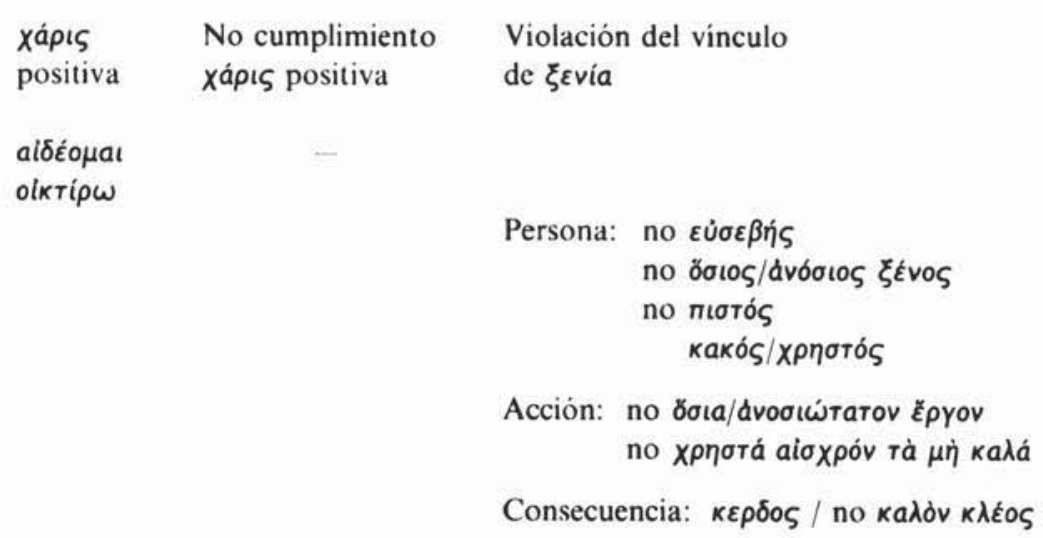

Con la noción significada por xápıs se relacionan los términos

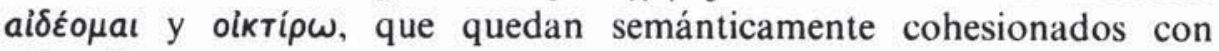
xápıs $"$ ".

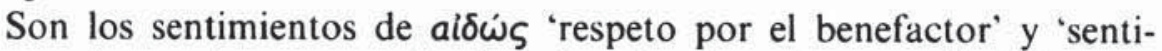
miento de vergüenza ante sí mismo', y de oikros 'compasión', los que llevan al hombre a socorrer a aquel otro ser humano que un día lo so-

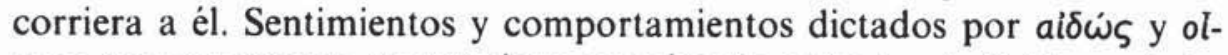
ктоৎ son rasgos que caracterizan ese vínculo entre los individuos, independientemente de su raza y de las relaciones entre sus naciones. Ésta es exactamente la situación que existe entre Hécuba y Odiseo y Agamenón.

Se observa que en el parámetro del no cumplimiento de la xápıs positiva, que es el caso de la conducta de Polimestor con la familia de Príamo, hay dos casillas vacías. Esto indica que es un término no marcado, un rasgo no pertinente del comportamiento de Polimestor. El ras-

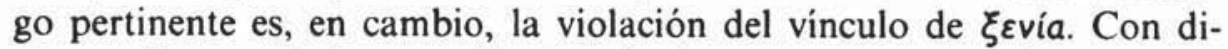
cha noción se relacionan todos los términos que vemos en el esquema.

Referidos a la persona que viola el vínculo de $\xi \varepsilon v i ́ a$ y a la acción

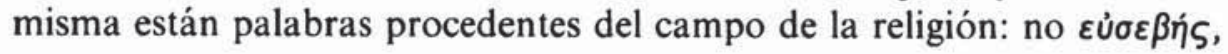

"Hec. 286-87. 


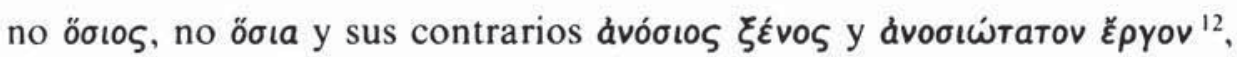
que evocan el carácter sagrado del vínculo de hospitalidad, cuya transgresión castiga la divinidad. El término kakós opuesto en contexto a

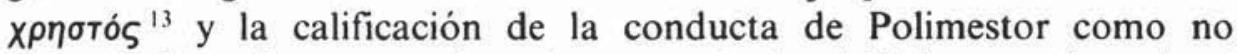

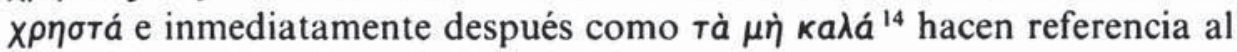
individuo y a la acción moralmente reprobable. Mientras que aioxpóv 15 aplicado a la conducta de Polimestor, en su contexto, hace referencia principalmente a lo que la sociedad condena más que al carácter intrín-

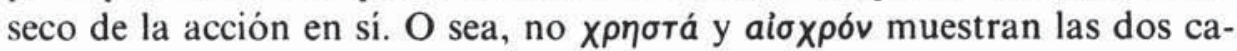
ras de una misma realidad: cómo es en sí y cómo es considerada respectivamente.

Para hacer referencia a aquello que reporta la violación del vínculo

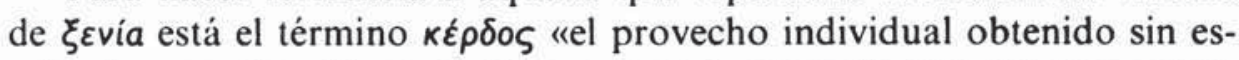
crúpulos morales" ${ }^{16}$, un término que en la tragedia está siempre cargado de connotaciones negativas. A él se opone en contexto aquello que

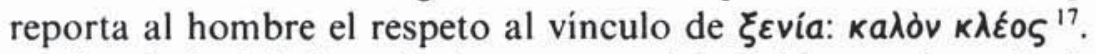

En el nivel de las relaciones entre el individuo y el estado hay en un haz una xápıs positiva y en el otro haz una xápıs negativa.

La xápıs positiva, en el nivel de las relaciones entre el individuo y el estado, se plantea a propósito de Aquiles y el ejército griego. El pueblo griego rinde al hombre de estado, una vez muerto, el reconocimiento agradecido por haber dado su vida por los intereses comunes.

La xápıs negativa es «el favor, cambiante de sujeto, según las circunstancias, que el pueblo otorga a sus dirigentes», "el favor falso, que consiste en la promesa irrealizable que el político hace al pueblo para ganar sus votos» y en "el falso favor, adulador, que el dirigente de una nación más débil argumenta haber hecho a una potencia más fuerte».

El primer y segundo caso son los que censura expresamente Hécuba en su diálogo con Odiseo. El tercero es la xápıৎ que Polimestor dice a Agamenón que ha hecho al pueblo griego, dando muerte al hijo de Hécuba, presunto enemigo de los griegos.

Se afronta, por tanto, el tema de la xápıs negativa en dos parámetros: el del hombre de Estado con relación a la politica interior y el del hombre de Estado en relación con la política exterior. Éste es el esquema:

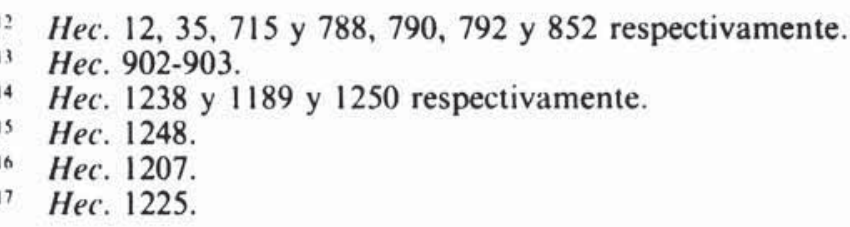




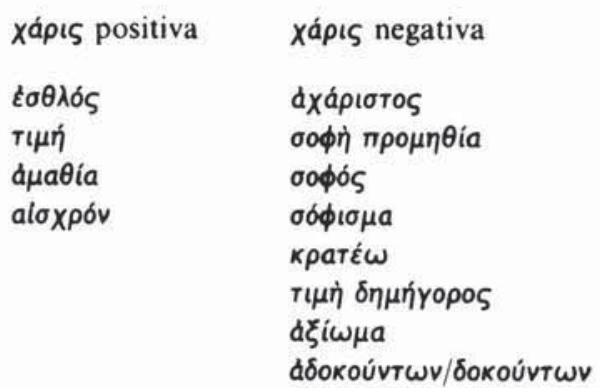

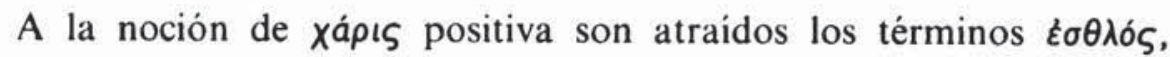

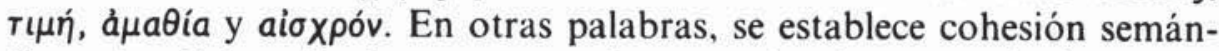
tica entre dichos términos, que quedan cargados de ese modo de connotaciones politicas.

Así, el hombre de estado que antepone los intereses de la colectividad a su propia vida es $\dot{\varepsilon} \sigma \theta \lambda o ́ \varsigma$, que se opone en contexto a kakó $\varsigma^{18}$. Por ello ha de recibir de parte de sus conciudadanos т $\mu \eta \dot{\eta}$ 'honores', que es la forma de manifestar externamente la xápı ${ }^{19}$.

Una conducta contraria por parte del pueblo sería una prueba de

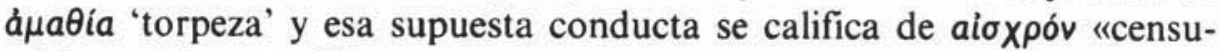
rable socialmente" ${ }^{20}$.

La xápıs negativa es aquella que corresponde a un hombre áxápı$\sigma \operatorname{roS}^{21}$ "desagradecido, incapaz de responder al favor con otro favor». $\mathrm{Y}$, efectivamente, ése es el panorama que se presenta en la obra. Odiseo por perseguir la xápıৎ negativa "el favor que otorga el pueblo" viola la xápıs positiva "el favor que debe a Hécuba». Polimestor escuda en la Xápıs negativa "aparentar que hace un favor a un pueblo con el que no tiene ningún vínculo previo" el incumplimiento de la xápıs positiva, a la que estaba obligado con la familia de Príamo.

En uno y otro caso el político, como individuo, traiciona al individuo al que debe agradecimiento, para granjearse el favor de la colectivi-

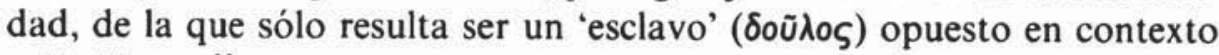
a $\varepsilon \lambda \varepsilon \dot{\theta} \theta \varepsilon \rho \varsigma^{22}$.

18 Hec. 307-308.

19 Hec. 309

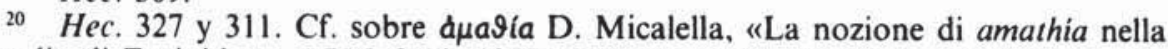
tragedia di Euripides", AFLL 8-10, 1977-1980, pp. 67-81, donde se concluye acertadamente que la amathia designa no una falta de saber momentáneo, sino la ignorancia en tanto estado mental, debida a la incapacidad de adaptarse o aprender, y que en Eurípides la palabra tiene un sentido más técnico y en todas sus acepciones un fuerte significado ético.

21 Hec. 252-257.

22 Cf. S. G. Daitz, "Concepts of freedom and slavery in Euripides' Hecuba", Hermes 99, 1971, pp. 217-226. 


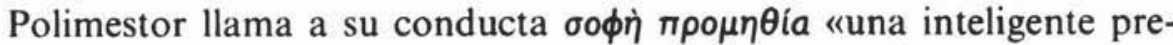
caución" ${ }^{23}$ y también Odiseo se llama asimismo $\sigma 0 \phi \delta \varsigma^{24}$. Esta es la $\sigma o$ фía del oportunismo político, aquella que se condena en el conocido pasaje en que Hécuba establece una oposición entre los que son roфoi en apariencia y los $\sigma o \phi o i$ en la realidad ${ }^{25}$. Se trata de una falsa sabiduria, que consiste en "un cálculo prudente que adecúa la conducta a las circunstancias, en pos del provecho propio". Ese falso ooфós utiliza para

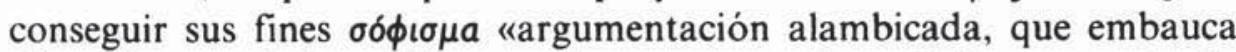
al pueblo, que le da crédito y emite su voto en favor de la propuesta" ${ }^{26}$.

Con esa conducta el político obtiene determinadas consecuencias ventajosas, bien precisadas también por el léxico:

- En el terreno de la opinión ajena, o de la consideración social,

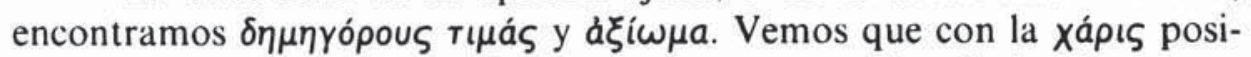
tiva se cohesionaba el término rı $\mu$ í «la cara positiva de los honores», «honores merecidos», "honores verdaderos». Con la xápıs negativa se cohesiona semánticamente también, pero totalmente cambiada de signi-

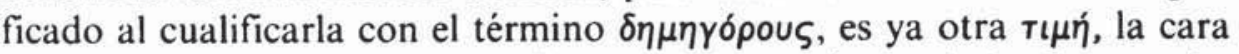
negativa de los honores "aquellos que son producto de la demagogia, que el pueblo tan pronto otorga como retira", "que son falsos en

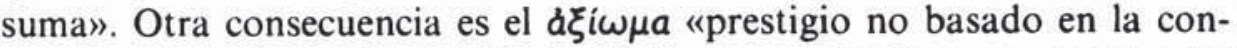
ducta recta", sino en la volubilidad de las masas. Es la cara negativa del término, que ha sido atraído por la noción negativa de тıрás $\delta \eta \mu \eta \gamma o ́-$ pous contaminándose de ella; es, pues, un significado puramente con-

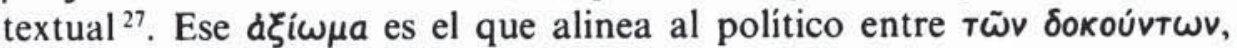

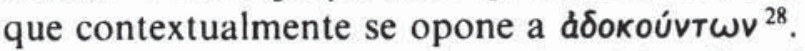

- En el terreno de la praxis, el hombre de estado que hace uso y

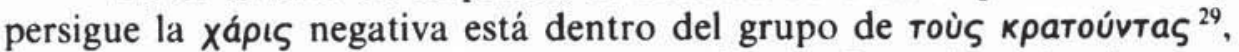

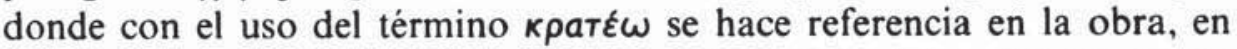
el autor y en general en la época, no al ejercicio del poder otorgado, sino al abuso de dicho ejercicio.

En cuanto a la polarización del léxico se ve que el término фìos se vincula tanto a la noción de la xápıs positiva como a la de la xápıs negativa.

\footnotetext{
Hec. 1137 y también 795.

Hec. 399.

Hec. 1192-93.

Hec. 258.

Hec. 293.

Hec. 295

Hec. 282-283.
} 
$\mathrm{Y}$ ello en los dos niveles: el de las relaciones entre individuos y el de las relaciones entre el individuo y el estado.

El término фílos cohesionado semánticamente con una u otra noción de Xápıs adquiere significados diferentes, o sea, tiene distinto referente.

Cohesionado semánticamente con la xápıs positiva, aquella cuyo rasgo pertinente es su carácter absoluto y no coyuntural, $\phi i \lambda$ os hace referencia a la persona con la que unen unos sentimientos y, en consecuencia, unos comportamientos que no guardan ninguna relación con el criterio de utilidad y que son de carácter inmutable.

El mismo término cohesionado semánticamente con la xápıs negativa, cuyo rasgo pertinente es su carácter coyuntural y mutable, hace referencia a unos vínculos que hacen nacer el criterio de utilidad y que, por tanto, son mutables según el rumbo que las circunstancias tomen.

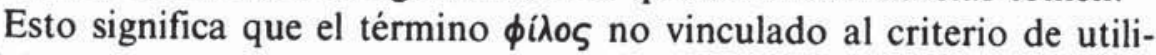
dad lo emplea Hécuba para hacer referencia al benefactor, sin que medie la diferencia de raza, ni las divergencias politicas ${ }^{30}$. En el nivel de las relaciones entre el individuo y su patria, Odiseo llama $\phi i \lambda \varsigma_{\varsigma}$ al benefactor de su pueblo, caso de Aquiles ${ }^{31}$.

El mismo término vinculado al criterio de utilidad hace referencia: o bien al aliado de guerra o al neutral, opuesto al enemigo de guerra

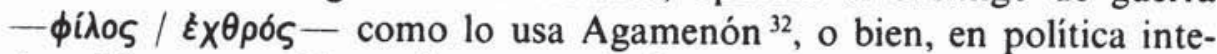

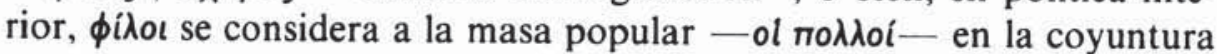
en que concede su favor al político, masa por la que el hombre de esta-

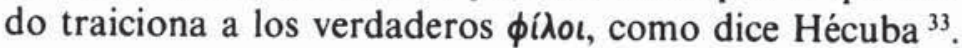

2.2. En Los Heraclidas el término recurrente es díkaıov. Éste es el que constituye el núcleo semántico. El mismo término hace referencia a dos nociones distintas ${ }^{34}$ : el rey de Atenas con el término díkalov significa un concepto de valor absoluto, que el hombre no puede cambiar, ya que Demofonte se refiere a la $\delta i ́ k \eta$ que consiste en la protección del débil que tutela Zeus y tiene por tanto un anclaje religioso. El campo de referencias de Yolao y del coro es el mismo que el de Demofonte. En cambio, el embajador de Argos con el término díxaıov significa un concepto relativo, que es susceptible de ser modificado por el hombre y por

30 Hec. 255.

Hec. 329.

Hec. 858-59.

Hec. 256.

34 No estoy de acuerdo con G. Zuntz, The political plays of Euripides, Man-

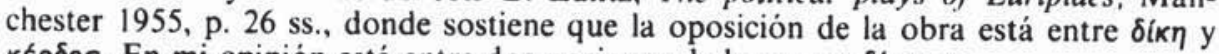

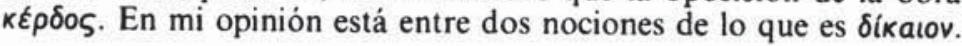




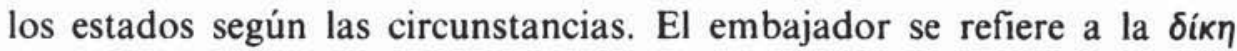
que consiste en el derecho legal que asiste al estado con relación a sus súbditos. Es obra humana, que deriva del vónoৎ de cada estado o de un $\psi \eta \dot{\phi} \iota \sigma \mu a$ del pueblo y no tiene caracter religioso.

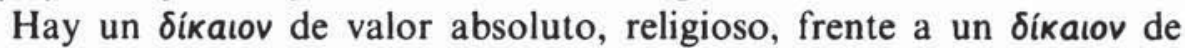
valor relativo, humano.

En torno a una y otra noción el léxico se cohesiona semánticamente adquiriendo funcionalidad política. El léxico restante se distribuye y se polariza.

La situación que se plantea en Los Heraclidas es semejante a la que se encuentra en Las Suplicantes en el sentido de que ambas son obras de propaganda del régimen político de Atenas, como es bien sabido ${ }^{35}$. Pero, como más adelante veremos, Las Suplicantes es exclusivamente una obra de propaganda política, tanto interior como exterior. Para ello se eligió un tema menos complejo en sí: el deber de enterrar a los muertos, un principio de derecho natural, que sensibilizaba muy especialmente las conciencias y que el ateniense había visto repetidas veces en escena, enfocado desde otros puntos de vista, como en la Antígona de Sófocles ${ }^{36}$.

En Los Heraclidas no ocurre lo mismo. Aquí la temática es más compleja porque el tema planteado está, en sí mismo, más sujeto a debate: es el de dar o no asilo político al exiliado, que ha sido condenado a pena de muerte por las leyes de su propio país, cuando éste reclama la repatriación a aquel otro pais que le ha dado acogida. Es un problema de politica exterior. Y el léxico hace ver que el régimen político de Atenas, o sea, su democracia, no es en Los Heraclidas un rasgo pertinente, sino su carácter de estado soberano en sus relaciones con los demás estados griegos. El rasgo pertinente, a diferencia de Las Suplican-

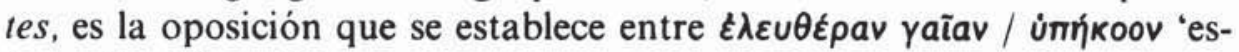
tado libre'/'vasallo'.

Problema muy espinoso de abordar el de la política exterior ateniense. Verdadera manipulación de los términos vamos a encontrar en Las Suplicantes cuando se toca este tema.

Eurípides se ve obligado a legitimar el ejercicio de la soberanía de Atenas en política exterior, incumpliendo normas de derecho interna-

35 Cf. sobre el tema J. W. Fitton, "The Suppliant Women and Herakleidae of Euripides", Hermes 89, 1961, pp. 430-61: A. Lesky, "On the Heraclidae of Euripides", YCIS 25, 1977, pp. 227-338, y R. Durand, "L'actualité politique dans les Héraclides d'Euripide. Éléments pour une datation", Orpheus 14, 1967, pp. 13-31.

${ }_{36}$ Sobre aspectos de léxico político en la Antigona de Sófocles cf. mi artículo citado en n. 6, donde hay una bibliografia amplia sobre el tema. 
cional, poniendo su conducta al amparo de la $\delta i k \eta$ religiosa. Enfrente se sitúa una $\delta i ́ k \eta$ que consiste en «el derecho que tiene el estado de ejecutar sus propias leyes sobre sus ciudadanos». A esta segunda סikn se atraen términos que hacen referencia a una política exterior puramente pragmática, fuera de connotaciones éticas.

La oposición entre las dos nociones significadas por el término se establece en dos niveles: 1) en un nivel supraestatal, que contempla las relaciones entre los individuos, o entre grupos unidos por vínculos de sangre y amistad, y 2) en el nivel de las relaciones entre estados.

En el primer nivel se encuentra solamente distribución léxica. En el segundo hay tanto distribución como polarización del léxico.

Éste es el esquema del primer nivel:

\begin{tabular}{|c|c|c|}
\hline ikaıv de valor & bsoluto & Síxaıov de valor relativo \\
\hline 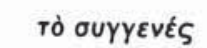 & + & - \\
\hline xápıs & + & - \\
\hline Tò aloxpóv & + & \\
\hline
\end{tabular}

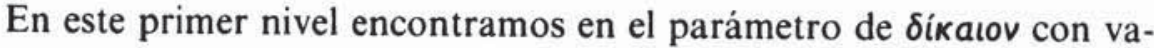
lor relativo una casilla vacía, lo que indica que el término positivo es $\delta i$ kaıov con valor absoluto.

Los sentimientos y las conductas vinculadas con «el respeto al pa-

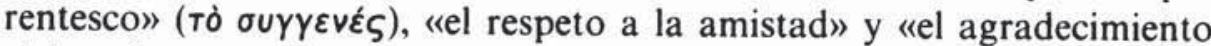
al benefactor» (xápıs) y «el respeto al propio honor», entendido el honor como la conducta moralmente ética acorde con las propias convicciones, se vinculan con la noción de díxaıov absoluto y religioso solamente, no con su contrario. Esto es interesante porque indica que se

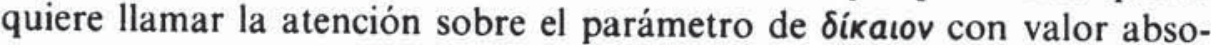
luto y religioso, como es normal en un término positivo.

En el segundo nivel nos encontramos con distribución y polarización del léxico en torno a una y otra noción de bíkalov.

En lo que afecta a la distribución léxica éste es el esquema:

\begin{tabular}{|c|c|}
\hline 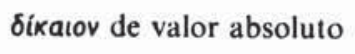 & $\delta$ íxaiov de valor relativo \\
\hline 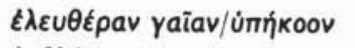 & vó $\mu \circ \varsigma$ \\
\hline 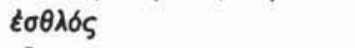 & 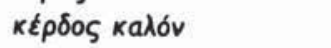 \\
\hline olkTOS & $\varepsilon \dot{\beta} \beta o u \lambda l a$ a $\mu \varepsilon i v \omega v$ \\
\hline & 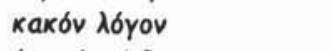 \\
\hline $\begin{array}{l}\text { no Tupavvis } \\
\text { xápıs }\end{array}$ & 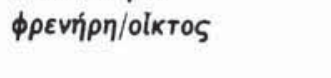 \\
\hline
\end{tabular}


Lo que se dilucida son las relaciones entre los estados griegos ${ }^{37}$. En

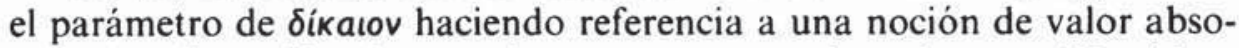
luto, la afirmación de que Atenas es un estado soberano ( $\dot{\varepsilon} \lambda \varepsilon u \theta \varepsilon \dot{\varepsilon} \rho a v$ yaĩav), no vasallo (úníkoov ${ }^{38}$ ) está legitimada por el hecho de que su misión se identifica con el concepto de $\delta i ́ k \eta$, entendida como protección del débil. Esto confiere a la soberanía ateniense una dimensión panhelénica, que consiste en velar por intereses que rebasan los límites del estado. Por esta razón los ciudadanos atenienses son calificados de $\dot{\varepsilon} \sigma \theta \lambda$ oí 'valientes' ya que anteponen su «sentido de la responsabilidad y honor

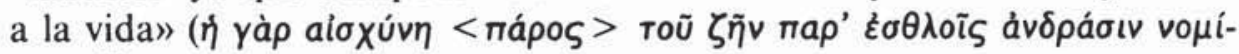
$\zeta$ ¿тal $\left.^{34}\right)$.

Por la misma razón su conducta está dictada por el sentimiento de compasión hacia el débil - olkros-, aunque éste no sea un ciudadano ateniense.

La manifestación que esta conducta tiene en la política interior, de la que al fin emana, aunque en esta obra la democracia ateniense no sea el rasgo pertinente, radica en que la soberania de Atenas está legitimada por la soberanía del pueblo de Atenas, o sea, por su sistema político, la "no tupavvís" como se la califica en Los Heraclidas ${ }^{40}$.

A un sistema político calificado de "no rupavví̧" se vincula también el término xápıs, debido a la capacidad de persuación de Demofonte, elegido libremente por el pueblo como su representante. Demofonte es el encargado de recordar al pueblo de Atenas su historia, en suma, de despertar del olvido su memoria, su conciencia ${ }^{41}$.

Como se ve, lo único que puede legitimar el hecho de que el estado ateniense no respete las normas de derecho internacional es que su conducta se vincule a la $\delta i ́ k \eta$ religiosa. Así la política exterior ateniense es intervencionista y belicista, pero dictada por el humanitarismo. Un panorama muy semejante volveremos a hallar en Las Suplicantes.

Cohesionado semánticamente con la noción de bíxaıov con valor re-

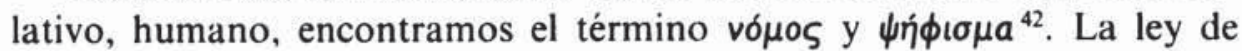
Argos votada y promulgada por decreto ha condenado a los exiliados a pena de muerte por delito politico.

17 Cf. sobre el tema Zuntz, op. cit., p. 26 ss.

3. Heracl. 62, 113, 198, 244 y 287.

39 Heracl. 200-201.

40 Heracl. 423. Nótese cómo en la obra cuando se habla de la soberania ate-

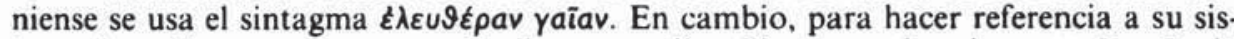
tema de gobierno es "no rupavvís" lo que se dice. No ocurre lo mismo en Las Suplicantes, donde la oposición, como veremos, es entre $\varepsilon \lambda \varepsilon u \vartheta \varepsilon \rho i a /$ Tupavvís.

41 Heracl. 334.

42 Heracl. 141. 


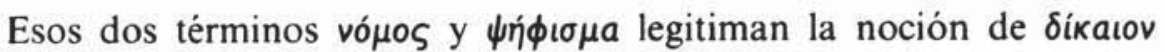
con valor relativo, humano. En nombre de esa legitimidad el embajador de Argos solicita de Atenas el respeto a las leyes de cada estado y, en consecuencia, una política no intervencionista. Los términos se han ele-

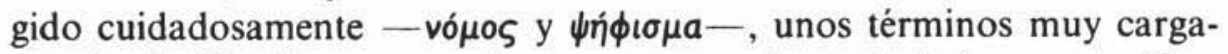
dos de significado para un ateniense y acreedores de todo respeto. Con sumo cuidado Eurípides ha puesto ambos términos en labios del embajador de Argos para hacer un alegato de la justicia contenida en la noción de Síkaıov que él defiende.

El léxico restante, que se cohesiona semánticamente con la noción

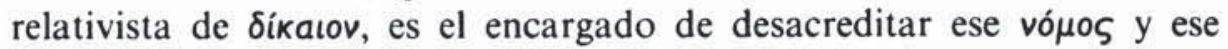
$\psi \eta \dot{\phi} \iota \mu_{a}$. Porque la solicitud de respetar las leyes internas de un estado griego y la segunda de no intervencionismo que hace el embajador de Argos a Atenas están hechas en nombre de una politica pacifista, pero pragmática y no humanitaria.

Así vemos que el no intervencionismo de Atenas tiene una consecuencia a nivel de estado $\left(\kappa \varepsilon \rho \delta \circ \varsigma^{43}\right)$. Que esa conducta se califica de $\kappa a-$ $\lambda o ́ v$. Se considera kałóv una política absentista, que tiende a conservar las buenas relaciones con las potencias de igual o parecido rango, sin prestar atención a la defensa del débil ${ }^{44}$.

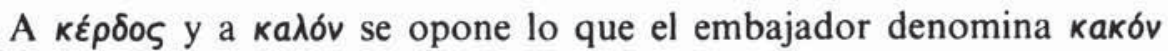

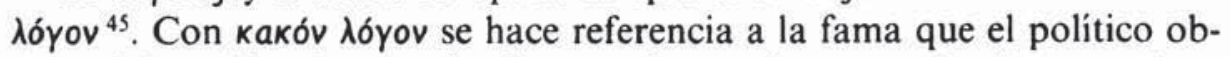
tiene del pueblo si no actúa de acuerdo con la conveniencia para el estado y se deja llevar por la compasión. Por tanto, el hombre de estado

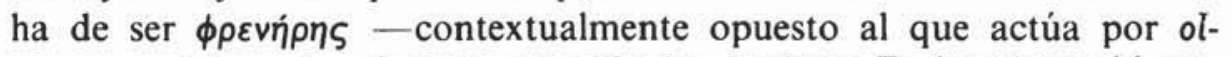

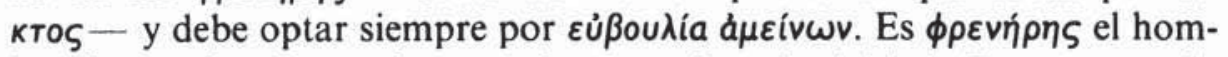
bre de estado que persigue $\kappa \varepsilon \hat{\varepsilon} \delta \delta \varsigma$ para la colectividad. En este caso lo es todo aquel que procede como los dirigentes de todos los demás estados griegos, negando el asilo político. Y, en la misma línea, zủßouגía á $\mu \varepsilon i v \omega v^{46}$ es la decisión más útil para el estado.

En lo relativo a la polarización léxica hay una serie de términos que emplean con distinto referente el embajador de Argos y Demofonte, o bien, en su misma línea, Yolao o el coro.

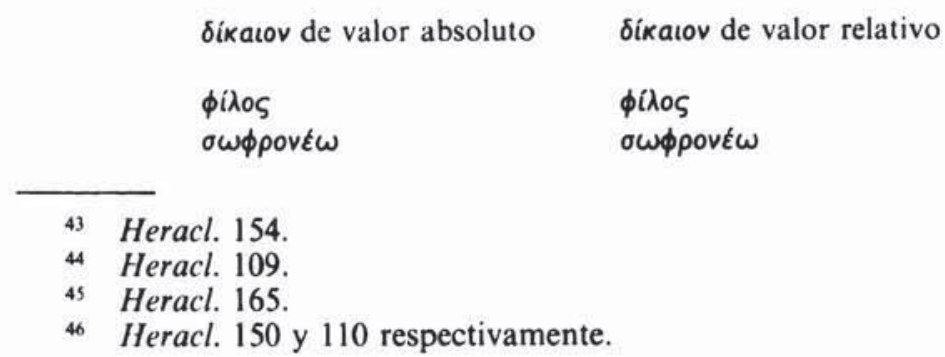




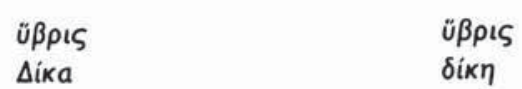

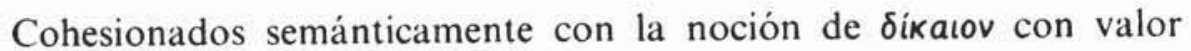
absoluto, religioso, se llama $\phi i \lambda o \varsigma$ al benefactor ${ }^{47}$. Con el verbo $\sigma \omega \phi \rho o-$ $v \varepsilon ́ \omega$ se hace referencia a una forma de pensar que lleva a actuar ayudando al débil, aunque para ello sea preciso arrostrar peligros a nivel de relaciones entre los estados ${ }^{48}$. En labios del coro es üßpıৎ atacar al indefenso, o sea, pretender arrancar de los altares al suplicante que se

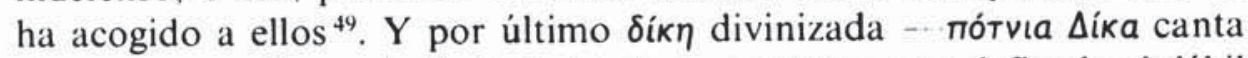
el coro se refiere a la Justicia tutelada por Zeus, que defiende al débil de los abusos del poder y castiga a aquel que aparta a un suplicante del altar ${ }^{50}$.

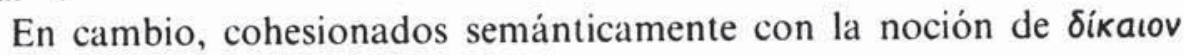
con valor relativo, 'el derecho legal', el embajador de Argos dice que los

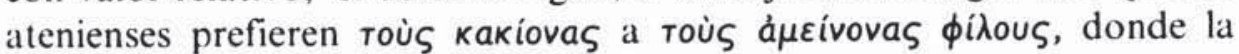
noción de фí̉os está unida al criterio de utilidad: los que no aportan beneficios se oponen a los que son más útiles, a los que es conveniente tener por amigos". El verbo $\sigma \omega \phi \rho o v \varepsilon ́ \omega$ significa "velar por los intereses del propio estado, por su seguridad, marginando cualquier conducta ética, de compasión con el débil» ${ }^{52}$. En labios del heraldo üßpıৎ es "amenazar a un embajador», representante legal de otro estado ${ }^{53}$. Y se llama $\delta i k \eta$ al "castigo", "la pena que se paga por la culpa», referido a la sentencia de muerte que pesa sobre los hijos de Heracles ${ }^{54}$.

Así pues, en el terreno de la manipulación de los términos por parte del hablante, o sea, en el de su polarización, los dos pilares fuertes de la argumentación del embajador de Argos, los contenidos por los térmi-

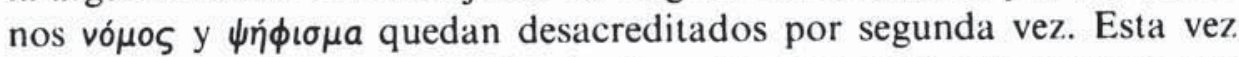
porque para salvar una noción de $\delta i k \eta$ «la pena legal que se paga por una culpa» necesariamente había que violar la otra noción de $\delta i \kappa \eta$, la divina, la пótvia $\Delta i k a$ de que habla el coro.

Sólo en Las Suplicantes veremos cómo se alcanza un nivel igual de propaganda política por medio del léxico.

2.3. En Andrómaca el término recurrente es $\phi \rho o v \varepsilon ́ \omega$. Lo utilizan

\footnotetext{
47 Heracl. 304, 309 y 312.

48 Heracl. 272.

49 Heracl. 924

so Heracl. 104.

Heracl. 177-178.

Heracl. 263.

Heracl. 280

4 Heracl. 60 y también 941 .
} 
Menelao, Andrómaca y Peleo. Con el mismo término se hace referencia a dos nociones distintas: hay una inteligencia aparente y otra inteligencia verdadera, la primera la confiere 'el azar' ( $\tau \cup ́ x \eta)$, la segunda viene dada por 'la verdad' $(\dot{a} \lambda \dot{\eta} \theta \varepsilon ı)^{55}$.

Éste es el núcleo semántico. Pero el esquema que presenta Andróma$c a$ es distinto al que ofrecen las obras anteriores. Casi todo el léxico está cohesionado semánticamente con la noción significada por $\phi \rho o v \varepsilon ́ \omega$ aparente. En el parámetro de $\phi \rho o v \varepsilon ́ \omega$ real encontramos casi siempre casillas vacías.

El término positivo, sobre el que se quiere hacer énfasis, es, pues, la inteligencia aparente. La inteligencia verdadera queda bien delimitada por carecer de todo aquello que se cohesiona semánticamente con la inteligencia aparente.

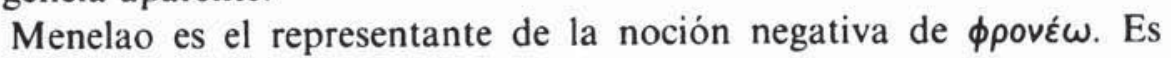
uno de los casos más claros en que se puede hablar de lenguaje a nivel del individuo. En el polo enfrentado se sitúa la noción positiva de $\phi \rho \circ-$ $v \varepsilon ́ \omega$; a ella hacen referencia primero Andrómaca, más tarde Peleo.

En mi análisis del léxico, en el enfrentamiento Menelao-Peleo, he marginado intencionadamente todos aquellos pasajes que suponen una crítica de las costumbres y la educación espartana, pues no son pertinentes.

Pienso que Andrómaca presenta uno de los casos más claros de cómo el hablante - Menelao en este caso - en torno a una misma noción central, elige uno u otro tipo de términos, según sea el interlocutor a que se dirija, Andrómaca o Peleo.

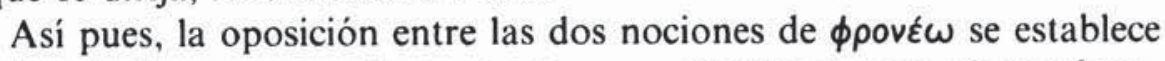
en dos niveles, como venimos viendo que es habitual, pero ahora el rasgo pertinente de uno y otro nivel es la relación hablante-oyente.

En un primer nivel el rasgo pertinente es la relación entre Menelao y Andrómaca, relación de vencedor-vencido, griego-no griego, representante de relaciones sociales legitimadas-representante de relaciones humanas no legitimadas.

El diálogo entre Menelao y Andrómaca anuncia cuál va a ser la no-

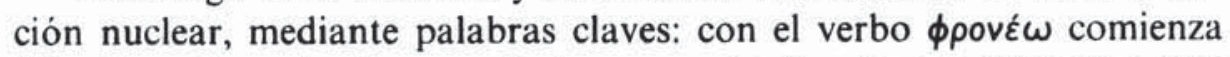
Menelao, dice asi: «has resultado menos inteligente que Menelao aqui presente, mujer» ${ }^{56}$. Con el verbo $\phi \rho o v \varepsilon \hat{\omega} \omega$ responde Andrómaca: «apariencia, apariencia... a quienes tienen buena fama por causa de la verdad, los considero afortunados, pero los que la tienen por causa de

\footnotetext{
ss Andr. 319 ss.

s6 Andr. 312-313.
} 
mentiras, no consideraré apropiado que la mantengan, sólo porque por

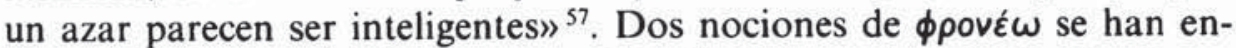
frentado. El resto del léxico es atraido al núcleo, adquiriendo funcionalidad política.

Ese $\phi \rho o v \varepsilon ́ \omega$ de que habla Menelao hace referencia a una inteligencia que consiste exclusivamente en el cálculo prudente del político que tiene la vista fija sólo en su propio beneficio y emplea para ello todo tipo de medios, impermeable a la ética de esos medios.

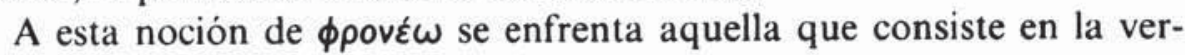
dadera inteligencia, una cualidad humana que radica en el conocimiento de lo vano de las apariencias y en el conocimiento del carácter efimero del cálculo prudente ${ }^{58}$. Con esa noción se cohesiona semánticamemte un solo término: $\varepsilon u ̈ \kappa \lambda \varepsilon ı$ เa.

Encontramos distribución léxica, en el sentido a que hice referencia antes. Éste es el esquema:

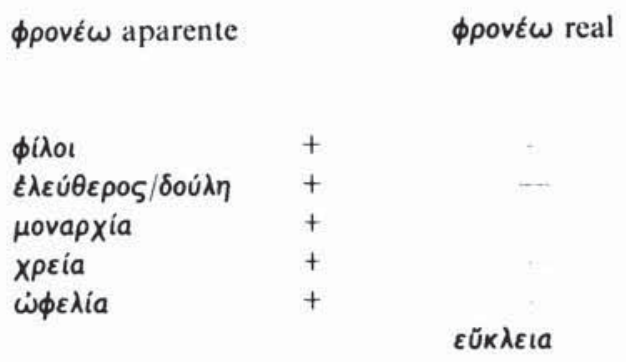

Cohesionado con la noción del "cálculo prudente del político", el

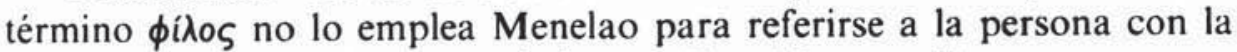
que le unen afinidades de sentimientos. Son $\phi i \lambda_{\text {o }}$ aquellas personas con las que se tienen establecidas alianzas, que hay que conservar $y$ en cierto modo respetar, porque reportan beneficios y en esa única medida. Por esa razón la alianza matrimonial convierte a Neoptólemo y Peleo en $\phi$ í̀o de Menelao.

Enfrente del фỉ̉os está aquel que nunca podría serlo, según su código pragmático, Andrómaca. De ahí que Menelao marque la oposición $\varepsilon \lambda \varepsilon \dot{\theta} \theta \varepsilon \rho \circ \varsigma$ / $\delta \circ \lambda_{\lambda} \eta$ con el significado de 'vencedor'/'vencido" ${ }^{59}$.

Menelao, en su categoría de $\varepsilon \lambda \varepsilon u ́ \theta \varepsilon \rho \varsigma_{\zeta}$ frente a $\delta o u ́ \lambda \eta$, llama a su si-

\footnotetext{
57 Andr. 319-323.

58 Sobre el significado de фpovéw en la tragedia cf. mi articulo «Sobre los periodos de la vida humana en la lírica arcaica y la tragedia griega (II)", emeritA 51, 1983, pp. 215-253.

59 Andr. 433.
} 
tuación como hombre público $\mu$ ovapxía ${ }^{60}$ 'poder absoluto', un término muy cargado de connotaciones negativas para un ateniense en cuanto opuesto a $\delta$ пократі́a.

Hay dos móviles en la conducta de Menelao, los dos móviles fundamentales que hacen suyos los grandes pragmáticos de la política griega:

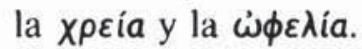

Los términos, como es sabido, proceden de los círculos ilustrados y están en Demócrito y Protágoras como causa y objetivo del desarrollo de la humanidad ${ }^{61}$. Euripides atrae los dos términos a la noción de la falsa inteligencia, la aparente, la que consiste en «el cálculo prudente en beneficio propio". Así, al quedar cohesionados semánticamente con $\phi \rho o v \varepsilon ́ \omega$ negativo, se cargan de connotaciones negativas solamente. La $\chi \rho \varepsilon a^{62}$ es el móvil de la conducta de Menelao y abiertamente confiesa a su antagonista, Andrómaca: "sábete bien que aquello que uno obtiene cuando tiene una necesidad perentoria de ello ( $\chi \rho \varepsilon i ́ a)$, eso es para cada cual más importante que conquistar Troya» ${ }^{63}$. El objetivo es la utilidad propia - $\dot{\omega} \phi \varepsilon \lambda i a^{64}$.

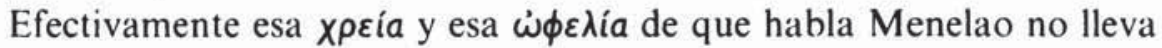
a ningún progreso de la humanidad, sólo al efímero y aparente triunfo del hombre sobre el hombre. Pero también es cierto que en sectores sociales muy amplios ambas nociones se vinculan con el término фpoveĩv. Este dramático hecho para la historia de Grecia y para la de la humanidad es el que mueve a Euripides a sostener que el término фpoveĩv está siendo manipulado y que bajo un mismo significante hay dos significados que entonces y siempre serán enemigos inconciliables.

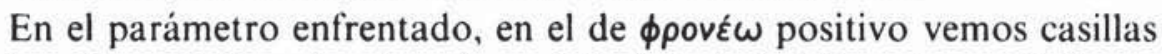
vacías. El verdadero $\phi \rho o v \varepsilon ́ \omega$ «la cualidad de la inteligencia» está divorciado de esa conciencia que establece barreras entre $\varepsilon \lambda \varepsilon u ́ \theta \varepsilon \rho \circ \varsigma$ / $\delta o u ́ \lambda \eta$, también de la creencia en que un hombre puede ostentar un poder absoluto - Hovapxía - y está divorciado de nociones como las significa-

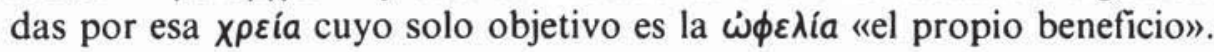

Sólo hay un término cohesionado semánticamente con $\phi \rho o v \varepsilon \dot{\omega}$ real, no aparente, la $\varepsilon u \check{\kappa} \lambda \varepsilon ı$ que en contexto se opone a $\delta \delta \xi a^{65}$. A la $\delta \delta \xi a$

60 Andr. 366.

${ }_{61}$ Cf. mi trabajo sobre Tucidides citado en $\mathrm{n}$. 5, donde hay bibliografia.

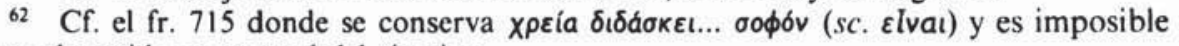
saber el sentido contextual del término.

${ }^{63}$ Andr. 368-69.

64 Andr. 539.

os No coincido con la generalidad de las interpretaciones de $\delta \delta \xi a$, que suele traducirse por "fama", así por ejemplo Euripides, Tragedias, vol I, Biblioteca Clásica 
«lo que la gente cree de Menelao, lo que aparenta ser» se opone lo que

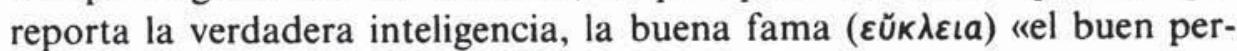
durar en la memoria y en la palabra de los otros hombres» ${ }^{66}$.

Eurípides, mediante el léxico, mediante su juego entre el vacío léxico y el solo término $\varepsilon u \check{\kappa} \lambda \varepsilon$ เa cohesionado con el verdadero $\phi \rho \circ v \varepsilon \omega$, ha condenado por y para la historia a todos los Menelaos, a todos los hombres que hacen concesiones a la apariencia violando $\mathrm{u}$ ocultando la verdad.

En el segundo nivel encontraremos una distribución léxica similar.

En cuanto a la polarización del léxico hay un solo término - фaũ$\lambda \circ \varsigma$ - que se utiliza haciendo referencia a dos nociones distintas ${ }^{67}$.

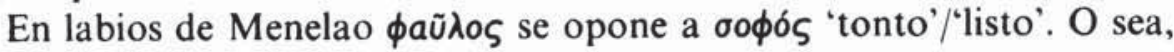

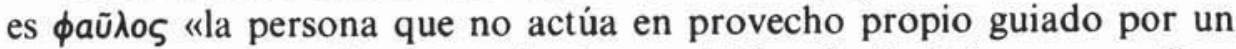
cálculo prudente». El mismo término en labios de Andrómaca se refiere al hombre que goza de $\varepsilon u \check{\kappa} \lambda \varepsilon ı a$ falsa - únò $\psi \varepsilon u \delta \tilde{\omega} v-$. De él la gente

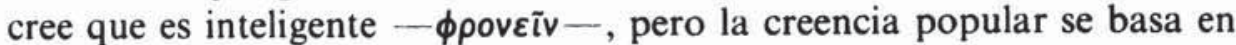
una coyuntura azarosa - Túx - . Ese hombre no debe ser objeto de estima - $\dot{\xi} \xi \omega \omega \omega-$ ni debe ser considerado afortunado - $\varepsilon \dot{\delta} \delta a \iota \mu \nu i \zeta \omega$.

En el segundo nivel el rasgo pertinente es la relación entre Menelao y Peleo, relación de vencedor-vencedor, griego-griego, pariente políticopariente politico.

El panorama que se encuentra uno es muy similar al que veiamos antes, pero ahora sólo hay distribución léxica, no polarización. Y del mismo modo que en el primer nivel el léxico está cohesionado semánticamente con la noción negativa de $\phi \rho o v \varepsilon ́ \omega$, quedando sólo casillas vacías en su contrario. Esto vuelve a indicar que el autor tiene interés en llamar la atención de su público sobre el término marcándolo.

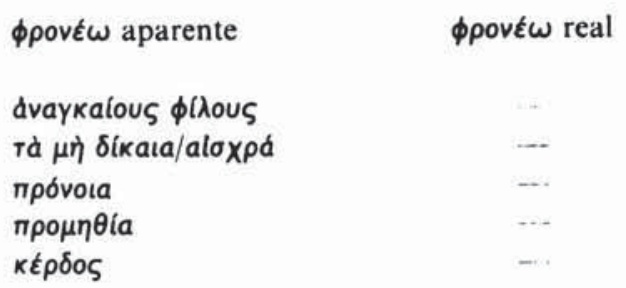

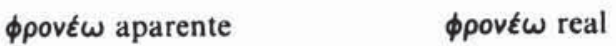

Menelao elige otro léxico en función de su oyente, Peleo. Ante Peleo

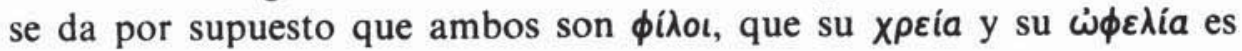

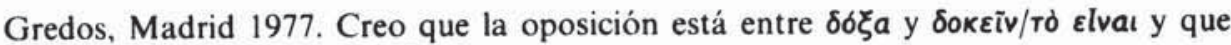
su correlato es ùnò $\psi \varepsilon \cup \delta \tilde{\omega} v / d \lambda \dot{r} \vartheta \varepsilon ı$ เa.

of Andr. 321.

67 Andr. 379 y 325.
} 
la misma y que ambos son $\varepsilon \lambda \varepsilon \varepsilon \dot{\theta} \theta \varepsilon \rho o$. Es un diálogo entre iguales y requiere más sutileza, cuidado en la elección de los términos y sobre todo en el orden de los mismos en la cadena del discurso. Así Menelao utiliza primero términos que hacen referencia solamente a los intereses que son comunes a Peleo y a él. Luego, cuando encuentra un oyente hostil, utiliza términos similares a los que usara para hablar a Andrómaca.

Menelao da por supuesto que considera a Peleo y a Neoptólemo $\phi$ i$\lambda o u$, pero le recuerda cuidadosamente que son amigos obligados, amigos en virtud de pactos previos, en virtud de un contrato matrimonial -ávaykaious фìous - que se opone en contexto a $\xi \hat{\varepsilon} v \eta^{68}$, a Andrómaca. De nuevo Eurípides eligió su léxico y su sintagma con mucho cuida-

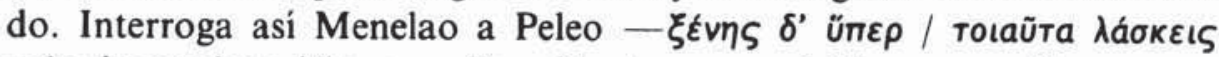

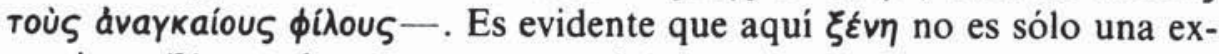
tranjera, $\xi \varepsilon v \eta$ es lo que se opone al avaykaĩos $\phi i ́ \lambda o \varsigma$, todo el universo humano que queda fuera de esos límites.

La conducta de Menelao la dicta «el aborrecimiento que le inspira lo que no es justo», que se opone a las palabras aloxpá que pronuncia Peleo $^{69}$. De nuevo Eurípides ha seleccionado su léxico, su frase y la modalidad interrogativa de la misma; pregunta así Menelao a Peleo: $\varepsilon l \tau^{\prime}$

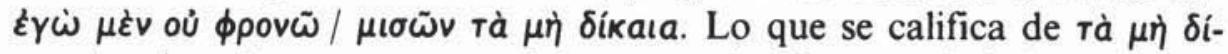
кala 'no justo' es que un no griego sea preferido a un ciudadano griego, en suma, que el hijo de Neoptólemo y Andrómaca usurpe el puesto de un hipotético hijo legítimo que pueda nacer de Hermione y Neoptólemo. Peleo no podría contestar negativamente a esta interrogativa retóri-

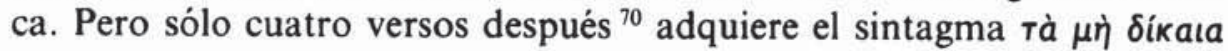

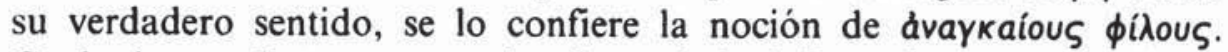
Cualquier conducta que se salga fuera de la defensa de ese coto esférico entra en las múltiples otras esferas de lo que recibe el calificativo de "lo no justo'. Y por esa razón las palabras de Peleo se califican de aloxpá "palabras que deshonran al propio Peleo", porque con ellas se defienden los derechos del individuo débil, no unido por vínculos legales, y ello en detrimento de aquellos otros vínculos contraídos con «amigos obligados", o sea, con aliados legales, de igual raza y de igual condición.

La conducta de Menelao la dicta igualmente la nрóvoı que supone "un ejercicio de la mente que se anticipa a los acontecimientos»" ${ }^{71}$. En

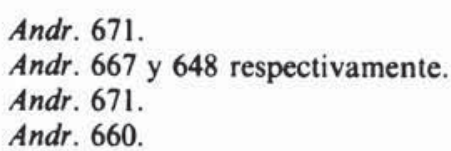


este caso consiste en «velar por lo propio, frente a lo extraño, o sea, por los intereses comunes a Peleo y a él».

En una segunda fase, cuando Peleo ataca abiertamente la conducta de Menelao, éste hace uso de otros dos términos: $\pi \rho \circ \mu \eta \theta i a$ y $к \varepsilon \varepsilon_{\rho} \delta \varsigma^{72}$.

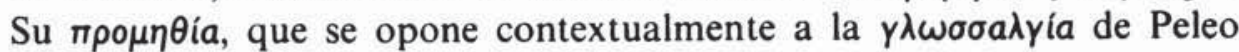
- como $\varepsilon \dot{v} \phi \rho o v \tilde{u} v$ se opone a la $\delta \rho \gamma \eta ́$ de Peleo en contexto-, es lo

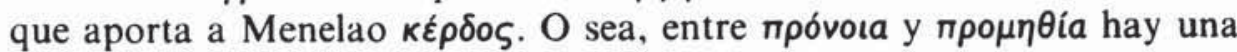
diferencia importante, la primera «vela por intereses comunes, colectivos», la segunda "vela por intereses exclusivamente individuales» y con ella se obtiene parejamente un "provecho para el individuo, que se opone directamente o indirectamente al de la colectividad».

\section{Dos TÉRMINOS DIFERENTES HACEN REFERENCIA A NOCIONES OPUESTAS}

3.1. Las Suplicantes como es sabido es una obra de propaganda del régimen de Atenas ${ }^{73}$, pero el análisis del léxico que desempeña funcionalidad política permite establecer algunas matizaciones importantes.

Los dos términos recurrentes son de una parte $\varepsilon \lambda \varepsilon v \theta \varepsilon \varepsilon \rho i a^{74}$ y de otra

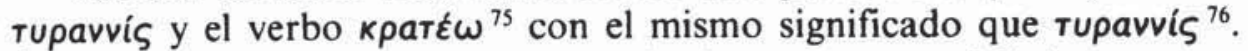
Éste es el núcleo. En torno a estos términos opuestos el léxico restante se cohesiona semánticamente, adquiriendo su funcionalidad politica. En torno a estos dos términos el léxico restante se distribuye, polariza y recategoriza, todo ello en dos niveles o parámetros: uno político-ético que se refiere a las relaciones entre los individuos dentro del marco del estado y otro político-ético que se refiere a las relaciones entre los estados.

En el primer nivel el rasgo pertinente de la oposición entre $\varepsilon \lambda \varepsilon u \theta \varepsilon p i a$ y rupavvis - 'libertad' y 'tiranía' - radica en que ambos términos nucleares hacen referencia a las formas de gobierno de Atenas y de Tebas respectivamente, o sea, hacen referencia a las diferentes formas de relación de los individuos dentro del marco del estado.

Se ve cómo en torno a un término el léxico se distribuye y se recategoriza de la siguiente forma.

En cuanto a su distribución, a la noción de $\varepsilon \lambda \varepsilon u \theta \varepsilon \rho$ ía se vinculan los

\footnotetext{
12 Andr. 690.

73 G. Zuntz hace un análisis muy inteligente de Las Suplicantes como obra de propaganda politica en op. cit., pp. 3-25, 58-62 y 88-96. Sobre algunos aspectos morales de la persona de Teseo cf. R. B. Gamble, "Euripides' Suppliant Women. Decision and ambivalence", Hermes 98,1970 , pp. 385-405.

74 Supp. 405, 438, etc.

75 Supp. 400, 411, 431.

76 Supp. 404, 439, 446.
} 


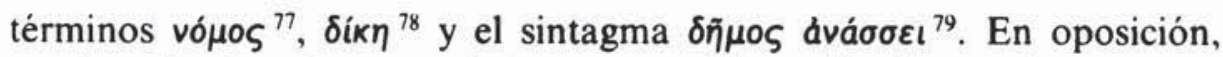
en el parámetro de rupavvís hay una casilla vacía. Esto es interesante, como ya hemos visto antes, pues demuestra que es el parámetro de $\varepsilon \lambda \varepsilon v$ $\theta \varepsilon \rho i a$ el término sobre el que interesa llamar la atención.

Así se hace evidente que vópos y $\delta i ́ k \eta$ son términos que solamente

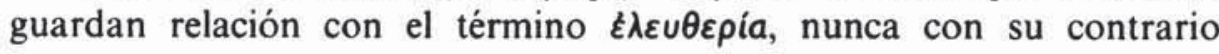
Tupavvís.

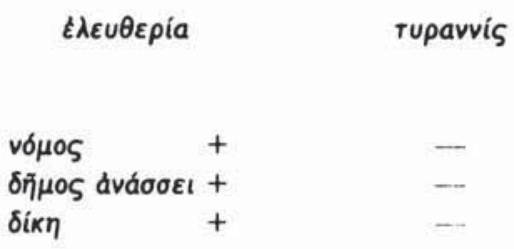

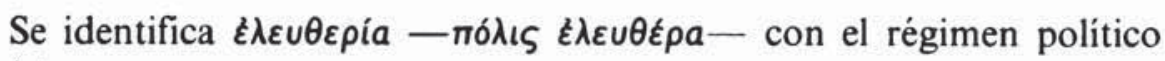
de Atenas.

En un plano teórico vó $\mu \varsigma_{\zeta}$ precisa los límites de la noción significa-

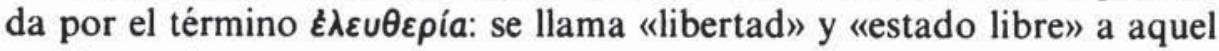
en el que el vómos - la ley escrita - es soberano.

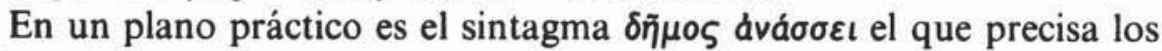

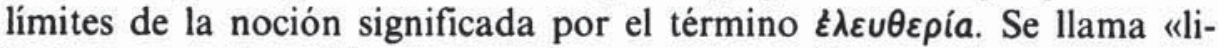
bertad" y "estado libre" a aquel en que el pueblo es soberano. En un

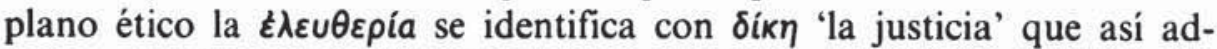
quiere una funcionalidad politica, que preside las relaciones entre los individuos dentro del marco del estado.

Se puede ver también aquí una recategorización, que es interesante a mi modo de ver: al parámetro de é $\lambda \varepsilon v \theta \varepsilon \rho \rho i a$ se vincula el término $\mu 0-$ vapxía. Encontramos en el parámetro de rupavvís de nuevo una casilla vacía.

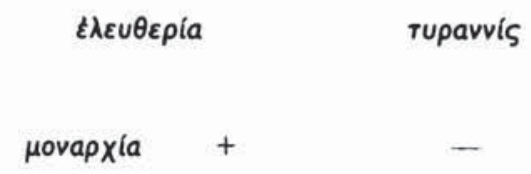

Lo que se dice es que «la $\varepsilon \lambda \varepsilon u \theta \varepsilon \rho i ́ a$ supone encaminar al $\delta \tilde{\eta} \mu \circ \varsigma$ ha-

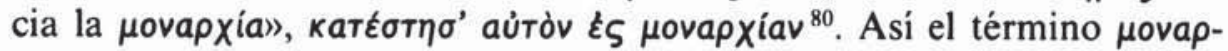

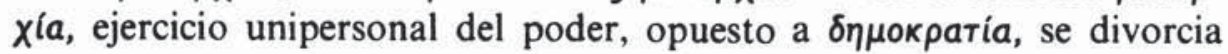

\footnotetext{
77 Supp. 378, 431, 541.

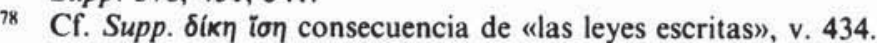

79 Supp. 406, 442.

80 Supp. 352.
} 
de su sentido primero, que lo vincula a rupavvís, para quedar vinculado a su opuesto $\varepsilon \lambda \varepsilon u \theta \varepsilon \rho i ́ a$ en una realización contextual nueva, con el significado de $« \delta \tilde{\eta} \mu \circ \varsigma$ en el ejercicio del poder con un carácter tan unitario y absoluto como si de un solo hombre se tratara". De modo que el término rovapxía se saca de su categoría léxica que lo vincula a la noción de individuo para ser recategorizado y vinculado a la noción de colectividad $-\delta \tilde{\eta} \mu \circ \varsigma$ - que ejerce el poder como si de un solo individuo se tratara.

En el segundo nivel el rasgo pertinente de la oposición entre $\varepsilon \lambda \varepsilon u \theta \varepsilon$ pía y Tupavvís radica en que ambos términos nucleares hacen referencia a dos tipos de relaciones político-éticas entre estados. El régimen político basado en la soberanía del pueblo de Atenas - $\varepsilon \lambda \varepsilon v \theta \varepsilon \rho i ́ a-$ se manifiesta en el exterior de una política belicista pero determinada por una ética humanistica. El régimen politico basado en la soberania del individuo de Tebas se manifiesta, en cambio, en una política pacifista pero basada en una conducta pragmática.

En torno a uno y otro término el léxico se distribuye y se polariza.

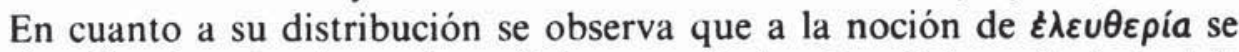

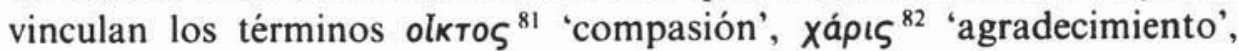

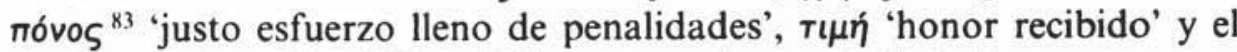

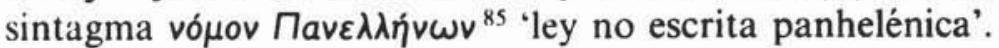

En oposición, en el parámetro de rupavvís encontramos de nuevo una casilla vacía, lo que demuestra que también en este segundo nivel es $\varepsilon \lambda \varepsilon \varepsilon \theta \varepsilon \varepsilon \rho i a$ el término positivo.

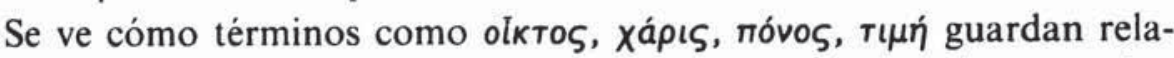

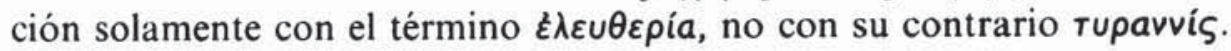

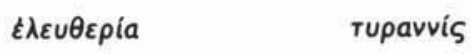

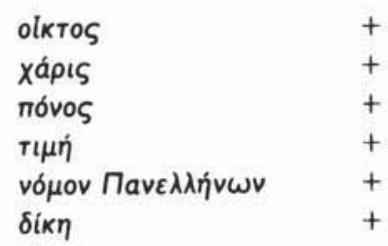

\footnotetext{
*1 Supp. 104, 168, 190.

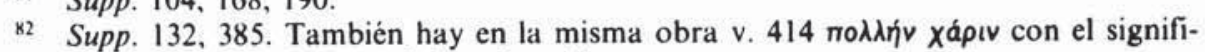
cado de "falsas promesas que adulan al pueblo".

${ }^{83}$ Supp. 179, 323 y 342 , etc.

84 Supp. 306.

*s Supp. 311, 526.
} 
En el plano teórico los términos olkтos y xápıs precisan los límites de la noción de $\varepsilon \lambda \varepsilon \varepsilon \theta \varepsilon \varepsilon \rho i ́ a$ en las relaciones de política exterior. El régimen de Atenas es el único que permite hacer de árbitro en litigios panhelénicos por dos razones: la de albergar para con el débil sentimiento de compasión y de agradecida memoria de los favores recibidos y la de respetar el vó $\mu$ os panhelénico, en este caso el vónoৎ que obliga a dar sepultura a los muertos.

En el plano de la acción el término nóvos precisa los límites de $\varepsilon \lambda \varepsilon v-$

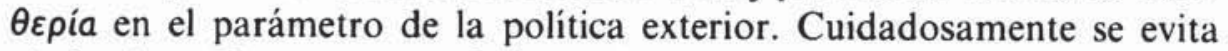

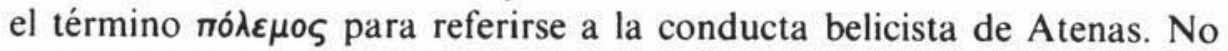
es belicismo, sino justo esfuerzo cargado de penalidades y sinsabores el intervencionismo de Atenas, porque es en defensa del oprimido.

En el plano de la valoración social $\tau \iota \mu \eta ́$ precisa los límites de $\varepsilon \hat{\imath} \varepsilon \cup \theta \varepsilon$ pía en el parámetro de la política exterior: la obtención de honores, consecuencia de los éxitos obtenidos en sus justas empresas.

En el plano ético la $\varepsilon \lambda \varepsilon u \theta \varepsilon \rho i a$ en el parámetro de las relaciones entre estados se identifica también con $\delta i k \eta^{86}$, que adquiere asi una segunda dimensión politica, que preside las relaciones interestatales. Son, pues,

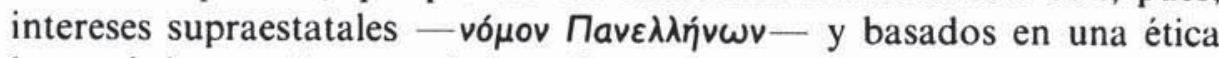
humanística -olkтos, xápıs - los que convierten en empresa justa - $\pi$ óvos - el belicismo ateniense.

El término contrario - tupavvís - se caracteriza por la ausencia de

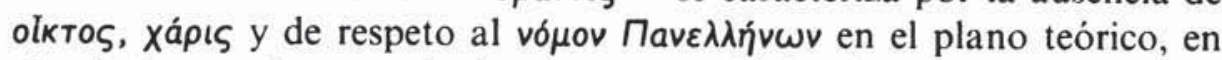

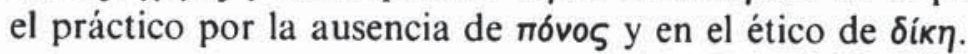

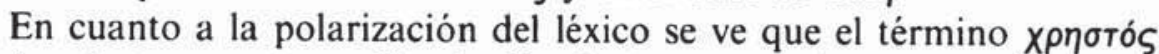
se vincula tanto a la noción de $\varepsilon \lambda \varepsilon u \theta \varepsilon \rho$ ía como a la de rupavvís en el nivel de las relaciones ético-politicas entre estados. Estamos ante un caso de polarización léxica.

Teseo emplea $\chi \rho \eta \sigma \tau a^{87}$ como opuesto a úßpıratai ${ }^{88}$. Son los estados que respetan las leyes comunes, no escritas, de los griegos y protegen al débil; su conducta es por tanto 'buena' en el sentido moralizado.

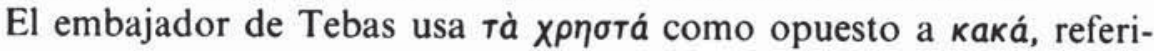
do a las elecciones que los estados pueden hacer en sus relaciones exteriores: las hay хрпбтá у какá, unas elecciones son 'convenientes', otras 'perjudiciales'. El término tiene por tanto un significado práctico fuera de valoración ética.

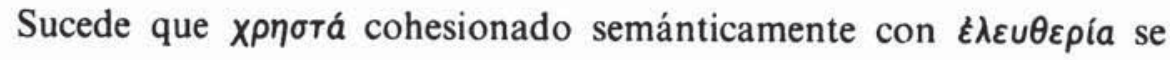

$\begin{array}{ll}86 & \text { Supp. } 328 . \\ 87 & \text { Supp. } 570 . \\ 88 & \text { Supp. } 487 .\end{array}$ 
carga de connotaciones éticas. En cambio cohesionado con rupavví se carga de connotaciones no éticas, sino pragmáticas.

3.2. En Las Fenicias el contexto tiene una tipologia en cierto modo similar al de Los Heraclidas, con anticipación-núcleo y cierre.

El núcleo lo constituyen las tres resis de Polinices-Eteocles-Yocasta. Pero está anticipado por las dos estructuras dialógicas: Polinices-Yocasta y Eteocles-Yocasta. Y hay recurrencia detrás del núcleo en la esticomitia Polinices-Eteocles ${ }^{89}$.

La tipología del núcleo no viene dada por la recurrencia de un mismo término, ni de dos términos opuestos. Los términos nucleares son ФіАотциіа e 'Ібо́тпs respectivamente. El rasgo pertinente que los distingue de los otros términos es el hecho de que están elevados a un rango sobrehumano, están divinizados. Un segundo rasgo pertinente se da en el hecho de que la oposición entre las dos nociones no se pone en labios de Eteocles y Polinices respectivamente. Ellos representan una y otra noción y el léxico que emplean uno y otro se cohesiona semántica-

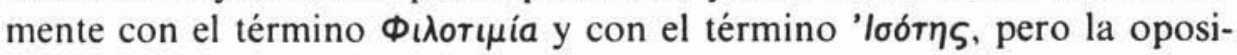
ción entre ambos términos y sus referentes es excéntrica, o sea, se pone en labios de Yocasta.

No se encuentra en la obra polarización léxica, no hay manipulación de los términos por parte de ningún personaje. Hay un caso de recategorización léxica de una gran relevancia, me refiero al término tupavvís. Sobre ello volveremos más adelante.

En cuanto a la distribución del vocabulario se observa que a la noción de філотці́a 'ambición' se vinculan casi todos los términos. En

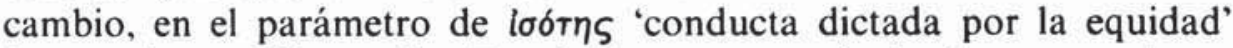
hay muchas casillas vacías. Esto indica, como se ha hecho notar reitera-

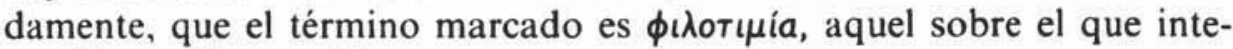
resa llamar la atención.

El caso de recategorización, que se puede ver en la obra, es impor-

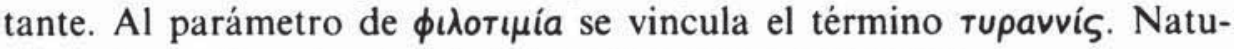

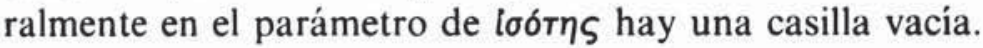

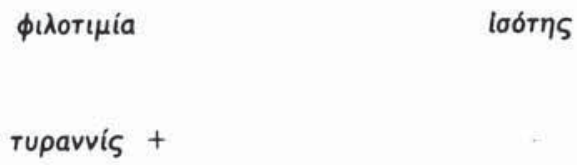

El término rupavvís es muy frecuente en la obra y lo emplean los

k9 Cf. sobre la tipologia del contexto en la introducción. 
tres personajes: Eteocles, Polinices y Yocasta. Se llama tupavvís a aquello que la ambición - філотціía - de Eteocles ha perseguido, a lo que ostenta y por lo que está dispuesto a afrontar todo tipo de situaciones, incluso la de llevar a la guerra a su país ${ }^{90}$.

Eurípides no usa el término tupavvís para referirse a una forma de

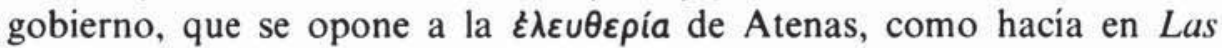
Suplicantes. En Las Fenicias tupavvís es el hecho de ser dueño del poder con carácter unipersonal y absoluto, pero dentro del propio estado democrático ateniense. Es el ejercicio de la rupavvis dentro de un sistema que, de derecho, es $\delta$ пократі́a.

Euripides habla de lo que está pasando en la realidad y fue un temor constante de la democracia ateniense: de la acumulación de poder real, no teórico, en un solo individuo.

Asi, lo que ha sucedido, es que el término tupavvís ha sido sacado de su categoria léxica que lo vinculaba a la noción de sistema de gobierno para vincularlo a la noción de individuo insertado en un sistema de gobierno, que consiste en la soberanía del pueblo, no del individuo

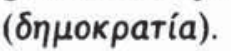

En otras palabras, se ha recategorizado el término. El efecto que sobre el público ejerce la recategorización léxica es sumamente impresivo. $\mathrm{Y}$ Euripides ha hecho girar toda su obra en torno a esta recategorización de un solo término, que usa con carácter recurrente. La obra trata

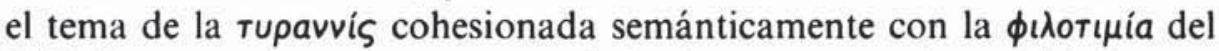
individuo que se puede generar y de hecho se genera dentro del sistema

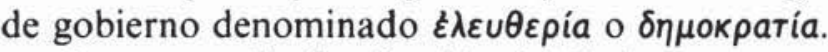

Respecto a la distribución del léxico tenemos el siguiente esquema:

\begin{tabular}{|c|c|c|}
\hline 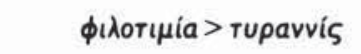 & & loótᄁs \\
\hline 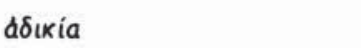 & & 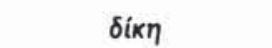 \\
\hline 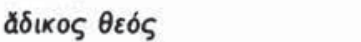 & & \\
\hline 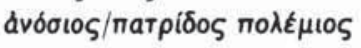 & & 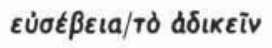 \\
\hline 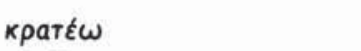 & + & $\ldots$ \\
\hline пגойтоร & + & - \\
\hline тініо丂 & + & \\
\hline 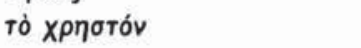 & + & - \\
\hline
\end{tabular}

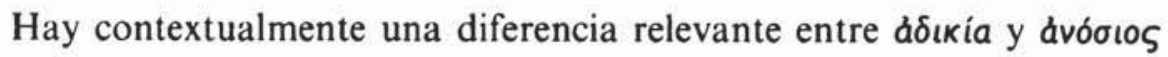
y sus contrarios $\delta i ́ k \eta$ у $\varepsilon \dot{\sigma \varepsilon \varepsilon} \beta \varepsilon ı$ la.

90 Cr. sobre el concepto de tirania en Las Fenicias la opinión de J. de Romilly con la que estoy de acuerdo en "Les Phéniciennes d'Euripide», $R P h$ 39, 1965, pp. 28-47, y en «Il pensiero de Euripide sulla tirania», Dioniso 43, 1969, pp. 175-87. 
El término ádıxia es recurrente ${ }^{91}$ : lo usa Polinices refiriéndose a la situación de la que es víctima. Yocasta dice que «la tiranía es una injus-

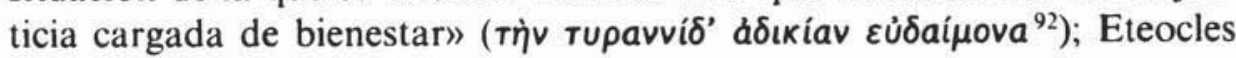
hace la tajante afirmación de que es «hermoso actuar injustamente si lo

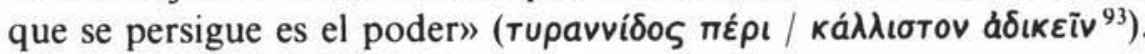

El término $\delta i ́ k \eta$ es también recurrente: lo utiliza Yocasta hablando a Eteocles ${ }^{94}$. Polinices refiriéndose al móvil de su conducta ${ }^{95}$. En el prólogo lo anticipa el anciano que enseña a la joven Antígona al campo de batalla ${ }^{96}$, y ésta refiriéndose a Polinices y sus aliados declara: «con jus-

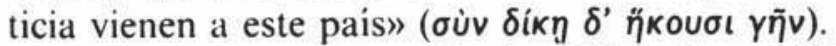

Es $\delta i k \eta$ el reparto equitativo del poder, es $\delta i ́ k \eta$ el respeto a la igualdad entre los ciudadanos. Es ádıcía su contrario, la acumulación de poder en un solo individuo.

En el mismo sentido, a la ambición que persigue la rupavvís se la

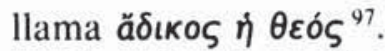

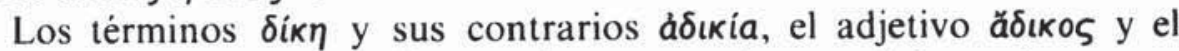
verbo $d \delta \iota \kappa \varepsilon \dot{\omega}$ carecen totalmente de connotaciones religiosas, hacen referencia a conceptos laicos, puramente humanísticos, de respeto o falta de respeto entre ciudadanos.

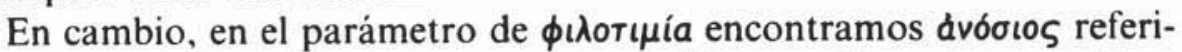

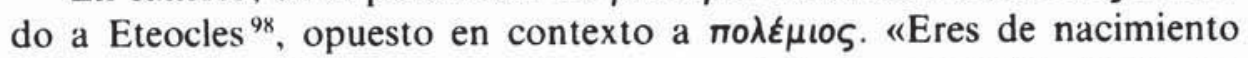
ávóøıo"», dice Polinices a su hermano, y éste le responde: "Pero no,

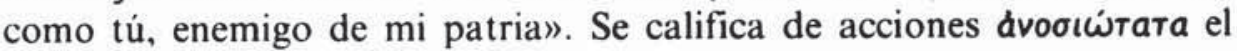
hecho de que Polinices se vea privado de su parte en el ejercicio del poder y de su patria ${ }^{99}$.

En el parámetro opuesto, con டбóтクৎ se cohesiona semánticamente

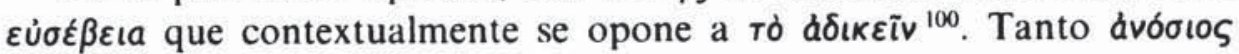
como $\varepsilon \dot{\sigma \varepsilon ́} \beta \varepsilon ı a$ son términos que hacen referencia a conductas que están relacionadas con el círculo de la familia ${ }^{101} \mathrm{y}$, como los preceptos de derecho natural - enterrar a los muertos etc.--, tienen un respaldo reli-

\footnotetext{
$91 \quad P h .608$.

${ }_{92} \quad P h .549$.

93 Ph. 524

94 Ph. 548

45 Ph. 490.

96 Ph. 154

${ }^{97} \quad P h .532$

98 Ph. 609.

99 Ph. 493.

$100 \quad P h .525$

101 Cf. en otras obras $\delta \sigma ı \varsigma_{\text {y }}$ ávóotos vinculado a círculos como el de la familia, la amistad, o bien a la protección del suplicante, a la obligación de enterrar a los muertos. Asi boios en Hec. 1235, Supp. 367, y dvóolos en Hec. 792, I.A. 1105, H.F. 1302, Hec. 852.
} 
gioso y una sanción en consecuencia, van cargados de connotaciones sacrales como las de "la impureza", o "la santidad». Este rasgo los dife-

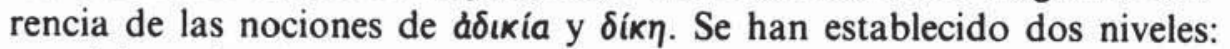
uno laico, vinculado al estado y a las relaciones entre sus ciudadanos y otro religioso vinculado a los lazos de familia y las relaciones entre los miembros de la misma.

El texto se encarga de ser el hilo conductor que muestra la existencia de estos dos niveles, que en la obra no se hacen entrar en conflicto $\mathrm{y}$ es importante subrayar este hecho ${ }^{102}$.

Los textos que sirven de hilos conductores son los que oponen

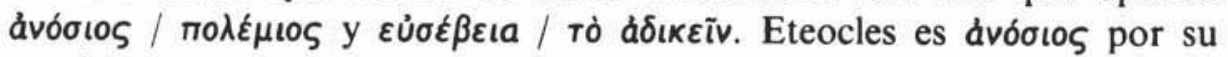

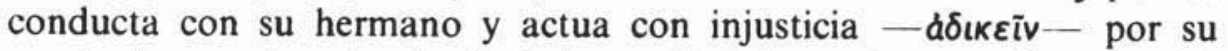
conducta para los demás ciudadanos. Polinices, al contrario, es noגर́$\mu \iota \varsigma$ de su patria por provocar una guerra civil, aunque sea con justicia, o sea, por sus relaciones con los demás ciudadanos, pero es $\varepsilon \dot{\sigma} \sigma \varepsilon \beta \eta ́ s ~ e n$ todo lo demás.

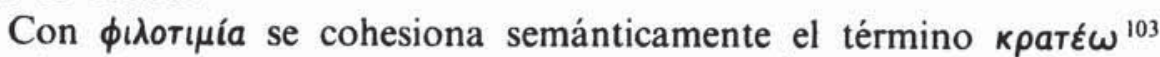
que significa el abuso del poder otorgado, como hemos visto que es frecuente, el término $\pi \lambda$ ioũro $\varsigma^{104}$, o sea, las consecuencias materiales que de ello derivan, у т $т \mu$, las consecuencias sociales que de ello derivan ${ }^{105}$.

Todo ello, Tupavvís divinizada, es lo que califica Eteocles de tò

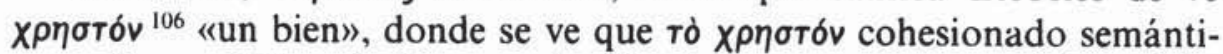

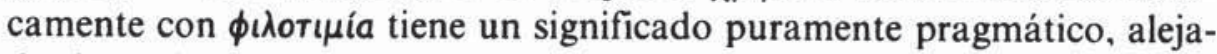
do de cualquier connotación ética.

\section{OPOSICIÓN DE NOCIONES EN EL NIVEL DEL SINTAGMA}

En Ifigenia en Áulide la noción nuclear gira en torno a la oposición

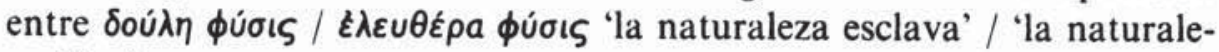
za libre'.

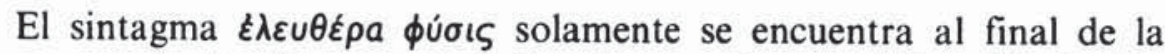
obra, cuando Aquiles se autodefine frente a los caudillos del ejercito griego, y también al final, en labios de Ifigenia, que denomina a su conducta causa de la libertad de Grecia $(\varepsilon \lambda \varepsilon u \theta \varepsilon \rho o ́ \omega)$. Pero la noción está anticipada al comienzo.

\footnotetext{
102 Este rasgo la diferencia radicalmente de la problemática presentada en Antigona.

103 Ph. 590.

104 Ph. 597.

105 Ph. 551.

106 Ph. 506-508.
} 


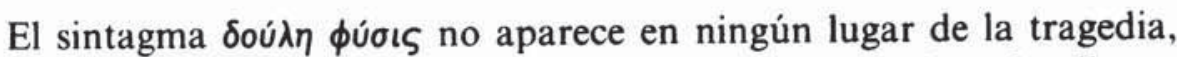
pero la noción de naturaleza esclava es una constante de toda ella, es el término marcado.

En el plano del significante dicha noción se desarrolla en dos parámetros interrelacionados: 1) mediante la recurrencia del término áváykn у ávaүкá̧ $\omega$ - el carácter condicionante de las circunstancias-, y 2) mediante sintagmas que en el plano semántico son portadores de las nociones, recurrentes, de «apariencia» / «realidad» ${ }^{107}$.

El diálogo lírico entre Agamenón y el anciano insinúa el núcleo semántico. El diálogo comienza estableciendo una división tajante entre

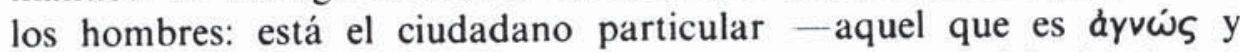
ák $\lambda \varepsilon \eta \dot{\zeta}$ 'desconocido' y 'carece de renombre' y pasa una vida sin riesgos

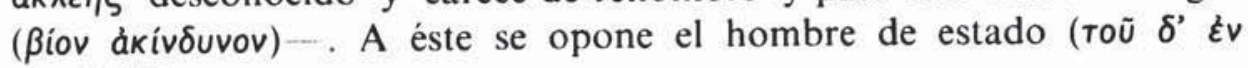
тинаĩ $\left.{ }^{108}\right)$.

Una vez establecida esta división, el miembro marcado, el hombre de estado se caracteriza en el plano del significante porque es el que tiene una expansión sintáctica, portadora de las nociones de los rasgos que le son pertinentes. Son estas dos: a) la vida del político está someti-

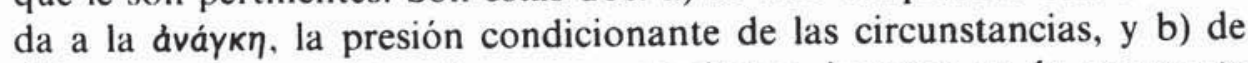
ahi que toda su existencia sea un espejismo, inmersa en la constante dualidad "apariencia» / "realidad».

El texto que sirve de expansión al término marcado del núcleo, el que va a ser relevante, el político, anuncia que este hombre no es $\varepsilon \hat{\imath} \boldsymbol{\varepsilon} \dot{u}-$ $\theta \varepsilon \rho \circ$. El otro término, el no marcado, el ciudadano particular, presenta una casilla vacía, no se anuncia que sea $\varepsilon \lambda \varepsilon \dot{\theta} \theta \varepsilon \rho \circ \varsigma$ frente al político.

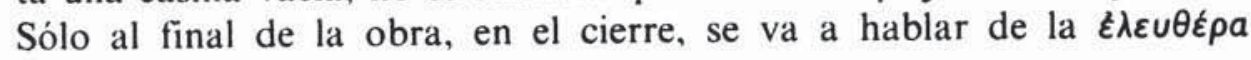
фúoıs.

La noción de la presión condicionante de las circunstancias, el tema

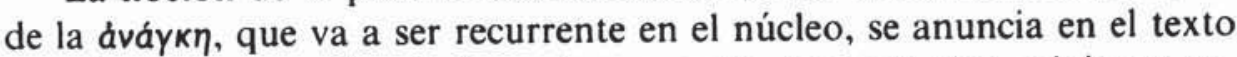
que sirve de expansión al elemento marcado, dice así: «las opiniones variopintas y dificiles de contentar del pueblo destrozan la vida del hom-

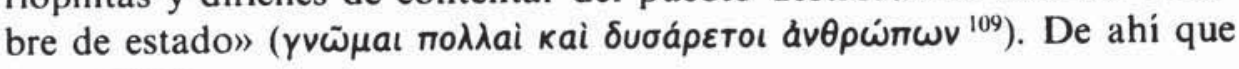
no sea libre.

La dualidad "apariencia» / "realidad» se refiere a las nociones que significan los siguientes sintagmas: «apariencia»: «en el hecho de ser un

107 En el anticipo presentado como comunicación en el VII CEEC (en prensa) sos-

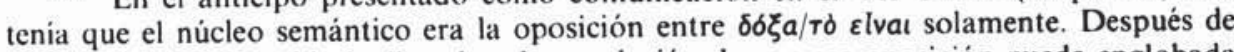
un estudio más detenido he llegado a la conclusión de que esa oposición queda englobada dentro de esta otra más amplia.

108 I.A. $17-18$ y 19 respectivamente.

109 I.A. 25. 
hombre público reside tò kaגóv roũ Bíou», dice el anciano / «realidad»:

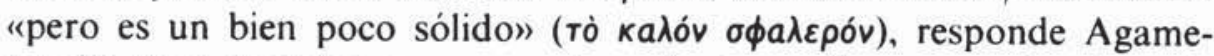
nón ${ }^{110}$. Y la dualidad es recurrente en texto contiguo: "apariencia»: "la

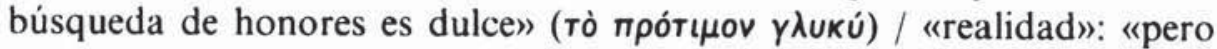

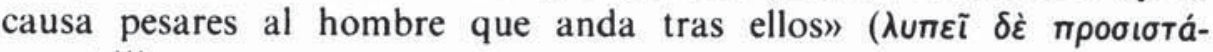
$\mu \varepsilon v o v)^{\prime \prime \prime}$.

La parte inicial de la obra, que anticipa el núcleo, responde a este esquema conceptual:

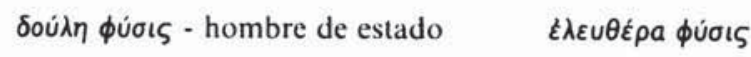

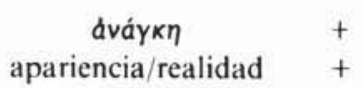

En el núcleo se van a desarrollar los dos rasgos que son pertinentes al hombre de estado, convirtiéndolo en un ser esclavo, a saber: la noción de áváyкn de la que habla Agamenón y las nociones opuestas apariencia / realidad, que desarrolla Menelao ${ }^{112}$. Los dos rasgos se cohesio-

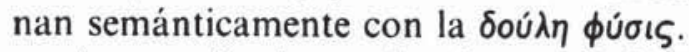

Agamenón desarrolla el tema de la áváyкn de forma recurrente. Primero cuando comprende que su intento de salvar de la muerte a Ifigenia ha fracasado, después de que un mensajero le haga saber que su hija acaba de llegar al campamento griego. Describe la situación en la

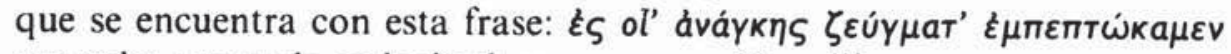
"en tales yugos de esclavitud nos vemos caídos»"113.

Más adelante, cuando su hermano Menelao le da a conocer su cambio de criterio y se opone decididamente al proyecto de sacrificar la vida de Ifigenia, Agamenón es incapaz de enfrentarse a todo el ejército y dice asi: "pero hemos llegado a una situación sin salida" ( $\varepsilon i \varsigma$ ávaykaías тúxas). Todo el ejército impone su criterio, que es ineludible

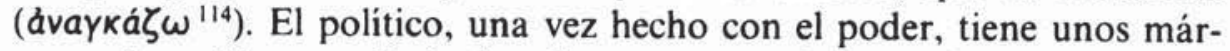
genes de acción muy limitados. Su comportamiento está sometido siempre a los condicionamientos de un criterio adoptado en el pasado del que ya no puede desdecirse sin ser objeto de censura. Su conducta está sometida siempre a los compromisos adquiridos con los otros hombres públicos, que son sus colaboradores o subordinados. El hombre de es-

$110 \quad$ I.A. 20.

III I.A. 21-22.

112 Como se ve el procedimiento de distribución es igual cuando se usan sintagmas que en el nivel del léxico.

113 I.A. 443

114 I.A. 511 y 513-14 respectivamente. 
tado depende siempre de la opinión, muy mutable, que de él tenga el pueblo. Ésa es la áváyкn de que habla Agamenón y que lo convierte en un ser privado de libertad.

Cuando por primera vez se nombra el tema de la áváyк ${ }^{115}$, recurrente como hemos visto, Agamenón lo desarrolla mediante una expansión que consta de dos miembros, son ellos los dos elementos nucleares

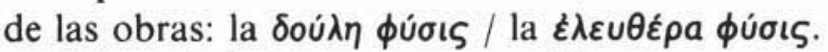

Dice asi el texto en esquema ${ }^{116}$ :

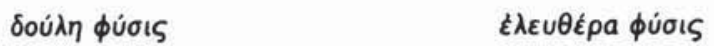

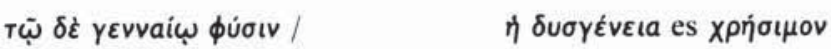

$$
\begin{aligned}
& \text { ăvoגßa таũTa }
\end{aligned}
$$

El ávì $\rho$ yvvaĩos, dice Agamenón, "no puede llorar y decir lo que piensa». Por el contrario su vida la caracterizan dos rasgos: a) tiene a

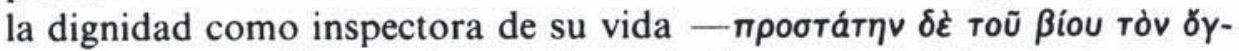

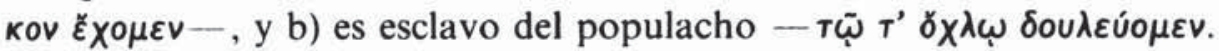

Así se ve cómo al desarrollar uno de los rasgos pertinentes de la

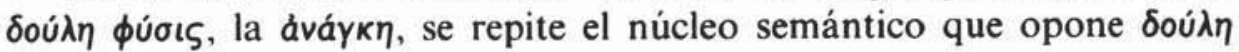

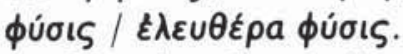

Menelao desarrolla ampliamente el tema de la dualidad "apariencia» / "realidad", constante de la vida del hombre de estado ${ }^{117}$. Su existencia transcurre a través de una pista con dos carriles: uno es el que ve el resto del mundo - es la apariencia-, el otro es su verdadero ser, que o bien las gentes no tienen oportunidad de contemplar nunca, o cuando la tienen, ya es tarde - es la realidad.

Hay una primera fase. Ésta se da cuando el individuo lucha por obtener el poder del que aún no disfruta ${ }^{118}$, "en apariencia no lo desea,

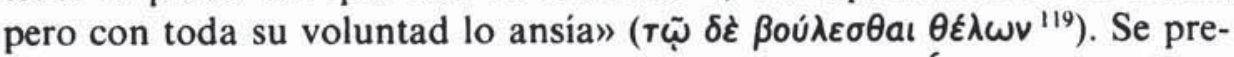
senta ante sus conciudadanos «accesible y humilde». Éste es un talante aparente. La realidad surge una vez que ha obtenido los votos populares, "se torna inaccesible y deja de ser amigo de quienes antes fueron sus amigos».

En una segunda fase, el hombre de estado, ya en el uso de la autori-

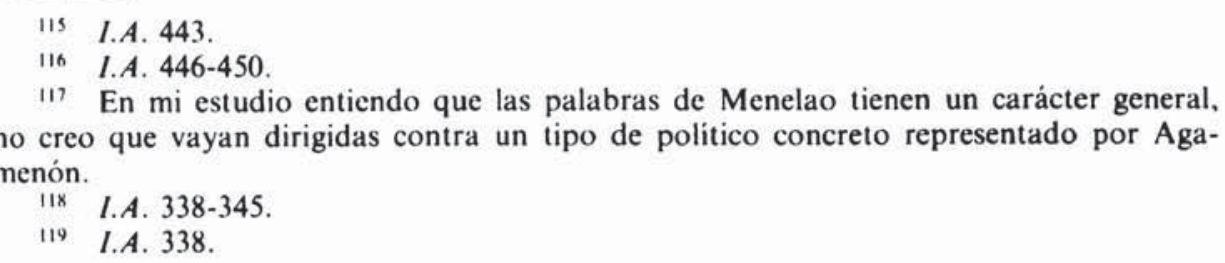


dad, da pruebas de la misma dualidad entre realidad y apariencia ${ }^{120}$. La realidad es que ante los primeros problemas que trae consigo el ejercicio del poder, se queda consternado y le asusta la sola idea de errar en la elección de una decisión y por ello perder el mando y la gloria. De grado - $\varepsilon \kappa \omega^{121}{ }^{121}$ - elige el partido que lo mantenga en el poder, sin ninguna clase de escrúpulos morales. Pero la apariencia es que su elección ha sido tomada contra su voluntad - $\beta i$ ạ $^{122}$.

Menelao lleva el hilo de su discurso de lo particular a lo general. Y en este otro plano también la apariencia se opone a la realidad: el pueblo se deja llevar por la apariencia, y por esa razón elige a sus dirigen-

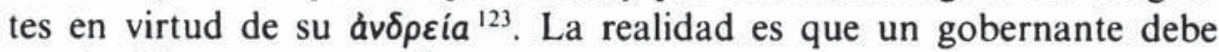
ser elegido por su voũ ${ }^{124}$.

La dualidad se quiebra y se pasa al plano de la realidad solamente. Dice asi Menelao: «son a millares los que se afanan por obtener el poder, pero luego retroceden ante él cobardemente" ${ }^{125}$. Y vuelve la dualidad, pues retroceden con cobardía ante la dura carga de responsabilidad, o sea, dejan de ser integros, consecuentes consigo mismos por una

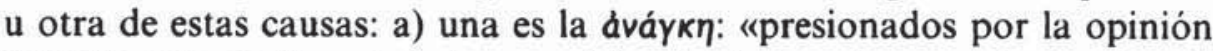
ininteligente de los ciudadanos» ( Tou ${ }^{126}$ ); b) otra causa es que la realidad se impone sobre la apariencia: "y otras justamente porque ellos mismos son incapaces de proteger la

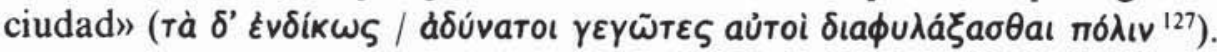

El núcleo de la obra desarrolla la noción sobre la que le interesa a Eurípides llamar la atención, el término positivo: la vida sometida a la esclavitud del hombre de estado, presionada desde el exterior por el carácter condicionante de las circunstancias, y desde el interior por esa dualidad que se ve obligado a mantener entre lo que aparenta ser y lo que realmente es.

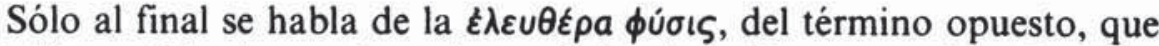
se había anticipado en el comienzo de la obra. Una naturaleza libre tiene el ciudadano que no ambiciona el poder, y una naturaleza libre tienen los jóvenes Aquiles e Ifigenia, que representan la cara luminosa de la vida ${ }^{128}$.

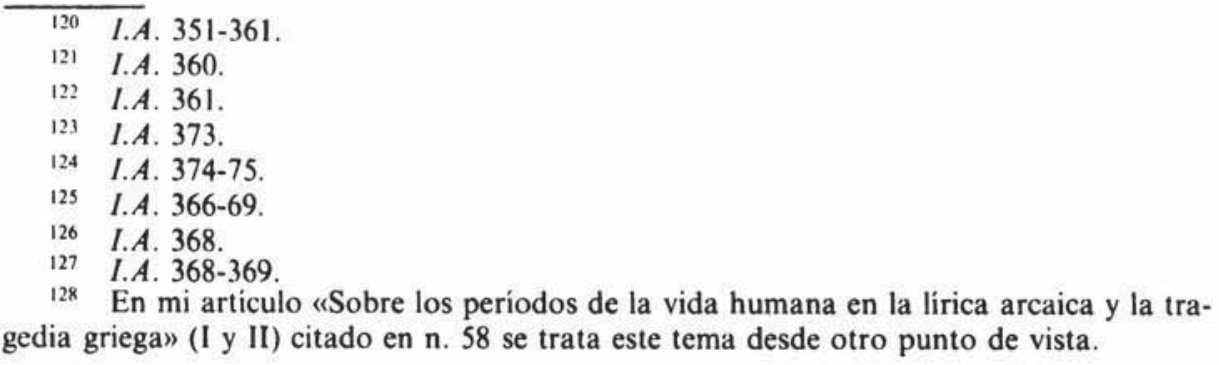




\section{Conclusiones}

Como se ha venido desarrollando con detalle en las páginas anteriores extraemos de nuestro estudio sobre el campo semántico de la política en Euripides las siguientes conclusiones.

1. Los estudios de semántica - sobre todo cuando tratan nociones abstractas, como las de la ética, la política, los sentimientos, etc. contextuales.

2. En la obra de Eurípides se encuentran dos tipologías contextuales, una de ellas muy condensada y aislada en consecuencia dentro de la obra, la que se da en Hécuba, Andrómaca y Las Suplicantes. Y la otra tipología, donde hay procedimiento de anticipación-núcleo y recurrencia cerrando, como sucede en Los Heraclidas, Las Fenicias e Ifigenia en Áulide.

3. El concepto de núcleo semántico es de suma importancia. Existen "palabras clave» o "sintagmas clave» en torno a los que se cohesiona semánticamente el vocabulario, adquiriendo funcionalidad política, como anticipaba en la introducción y se ha ido desarrollando a lo largo del trabajo.

El núcleo semántico en las obras de Eurípides presenta tres tipologias, como también se anunciaba en la introducción:

3.1. El mismo término haciendo referencia a dos nociones opuestas, como hemos visto en Hécuba, Los Heraclidas y Andrómaca.

3.2. Dos términos distintos haciendo referencia a nociones opuestas, como hemos estudiado en Las Suplicantes y Las Fenicias.

3.3. Oposición de dos nociones por medio de sintagmas, no de léxico, como se ha analizado en Ifigenia en Áulide.

4. Las oposiciones se establecen sistemáticamente sobre dos términos. Éstas, a su vez, se desarrollan casi siempre -así Hécuba, Andrómaca, Los Heraclidas, Las Suplicantes y Las Fenicias - en dos parámetros o niveles. Otras veces hallamos un solo nivel de desarrollo, como sucede en Ifigenia en Áulide.

5. Los conceptos de distribución, polarización y recategorización léxica son de una gran importancia y constituyen, junto con la tipología del contexto y el concepto y tipologías del núcleo semántico, el tercer gran pilar teórico sobre el que se asienta este trabajo. Esto se ha ido desarrollando detenida y rigurosamente en sus lugares respectivos.

\section{Mercedes Vílchez}

